Discussion Paper No. 07-031

\title{
Earnings Prospects for People with Migration Background in Germany
}

Alisher Aldashev, Johannes Gernandt, and Stephan L. Thomsen

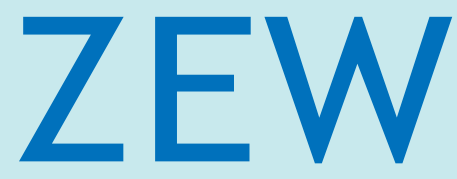

Zentrum für Europäische Wirtschaftsforschung $\mathrm{GmbH}$

Centre for European

Economic Research 
Discussion Paper No. 07-031

\title{
Earnings Prospects for People with Migration Background in Germany
}

\author{
Alisher Aldashev, Johannes Gernandt, \\ and Stephan L. Thomsen
}

Download this ZEW Discussion Paper from our ftp server:

ftp://ftp.zew.de/pub/zew-docs/dp/dp07031.pdf

Die Discussion Papers dienen einer möglichst schnellen Verbreitung von neueren Forschungsarbeiten des ZEW. Die Beiträge liegen in alleiniger Verantwortung der Autoren und stellen nicht notwendigerweise die Meinung des ZEW dar.

Discussion Papers are intended to make results of ZEW research promptly available to other economists in order to encourage discussion and suggestions for revisions. The authors are solely responsible for the contents which do not necessarily represent the opinion of the ZEW. 


\section{Non-technical Summary}

People are said to have a migration background if they themselves or their parents are foreign born or possess foreign citizenship or did so in the past. According to this definition, in 2005 about 19 percent of Germany's population have had a migration background. More than half of the people with migration background, i.e. about $10 \%$ of Germany's population, are German citizens. The share of foreigners living in Germany amounts to 9\% (Statistisches Bundesamt, 2006). Hence, using citizenship (as many studies do) to analyze economic issues of immigration may be problematic for two reasons. On the one hand, a quite substantial share of persons with migration background is neglected in the group of interest, and, on the other hand, the reference group (native Germans) may be contaminated by effects from naturalized immigrants.

This paper utilizes a wider definition covering all persons with migration background to analyze the earnings prospects. To shed light on differences to the common use of citizenship, estimates are presented in comparison to foreigners and German citizens. The second question of the paper is whether degrees obtained in Germany lead to better earnings prospects compared to degrees obtained abroad for persons with migration background.

The empirical application is based on data from the waves 1995 to 2005 of the German SocioEconomic Panel. The results show that persons with migration background have similar earnings prospects to foreigners. Moreover, earnings prospects for native Germans do not differ much from those of German citizens. Therefore, using citizenship to approximate natives and nonnatives when analyzing earnings issues seems to be reasonable. For the second question, the estimates affirm higher earnings to educational attainment in Germany independently of gender and skill level. 


\title{
Earnings Prospects for People with Migration Background in Germany*
}

\author{
Alisher Aldashev ${ }^{\dagger}$, Johannes Gernandt ${ }^{\ddagger}$ and Stephan L. Thomsen ${ }^{\S}$ \\ ZEW, Mannheim
}

First draft: May 21, 2007

This version: July 2, 2007

\begin{abstract}
Less than half of the people with migration background living in Germany possess foreign citizenship. Hence, using citizenship to analyze economic issues of immigration may be problematic for two reasons. On the one hand, a quite substantial share of persons with migration background is neglected in the group of interest, and, on the other hand, the reference group (native Germans) may be contaminated by effects from naturalized immigrants. This paper utilizes a wider definition covering all persons with migration background to analyze the earnings prospects. To shed light on differences to the common use of citizenship, estimates are presented in comparison to foreigner and German citizens. The results show that persons with migration background have similar earnings prospects to foreigners. Moreover, earnings prospects for native Germans do not differ much from those of German citizenship. Therefore, using citizenship to approximate natives and non-natives when analyzing earnings issues seems to be reasonable. A second question of the paper is whether degrees obtained in Germany lead to better earnings prospects compared to degrees obtained abroad for persons with migration background. Independently of gender and skill level, the estimates affirm higher earnings to educational attainment in Germany.
\end{abstract}

Keywords: Migration background, earnings prospects, education, Germany

JEL Classification: J61, I12, J15

\footnotetext{
${ }^{*}$ We thank Bernhard Boockmann, Wolfgang Franz, Christian Göbel and Friedhelm Pfeiffer for valuable comments, and Philipp Eisenhauer for his research assistance. The paper has benefited from discussion at seminars at ZEW and University of Dortmund. The usual disclaimer applies.

${ }^{\dagger}$ Alisher Aldashev is Research Fellow at the Centre for European Economic Research (ZEW), L 7,1, D-68161 Mannheim, e-mail: aldashev@zew.de.

${ }^{\ddagger}$ Johannes Gernandt is Research Fellow at the Centre for European Economic Research (ZEW), L 7,1, D-68161 Mannheim, e-mail: gernandt@zew.de.

${ }^{\S}$ Stephan L. Thomsen (Corresponding Author) is Research Fellow at the Centre for European Economic Research (ZEW), L 7,1, D-68161 Mannheim, e-mail: thomsen@zew.de.
} 


\section{Introduction}

People are said to have a migration background if they themselves or their parents are foreign born or possess foreign citizenship or did so in the past. According to this definition, in 2005 about 19 percent of Germany's population have had a migration background. More than a half of the people with migration background, i.e. about $10 \%$ of Germany's population, are German citizens. The share of foreigners living in Germany amounts to 9\% (Statistisches Bundesamt, 2006). Two groups account for the vast majority of persons with migration background in Germany: On the one hand, persons and descendants from South European (including Turkey) and North African countries, who were recruited from the 1950s to early 1970s. Many of these people still possess a foreign citizenship (further defined as foreigners), but there are also quite a few who were naturalized (further defined as German citizens with migration background). On the other hand, ethnic Germans from the former Soviet Union and Eastern European states who resettled mainly after the late 1980s (further defined as resettlers). ${ }^{1}$ Ethnic Germans (and their family members and descendants) are equal to native Germans by law and can receive German citizenship at the time of or shortly after immigration to Germany. However, for a number of reasons, e.g., language difficulties, different education systems in the home countries, possible non-transferability of skills acquired in the home country to the German labor market, or cultural differences, they are likely to have different earnings prospects from native Germans. Moreover, in the light that for people aged 25 or younger the share of persons with migration background is about one quarter and for children below six even about one third (Statistisches Bundesamt, 2006), which means that the percentage of people with migration background in the population of working age is likely to rise in the future, it becomes necessary to analyze how people with migration background perform in Germany's economy.

In this paper, we focus on earnings prospects for people with migration background. The analysis is descriptive by nature. In contrast to US studies that distinguish races or ethnics (see, e.g., Altonji and Blank (1999) for an overview), studies for Germany typically refer to citizenship to analyze differences between immigrants and natives. However, comparison of earnings prospects based on nationality only could be problematic for a number of reasons. There may be substantial differences between native Germans and German citizens with migration background, because the reference group (German citizens) could be contaminated by naturalized immigrants. The question which arises in this respect is whether we can generalize the results of the studies comparing German citizens and foreigners to be valid also for the comparison between native Germans and persons with migration background. In the context of earnings, this question implies if there is a systematic significant variation between the earnings profiles of foreigners and people with migration background or of foreigners and German citizens with migration background. In addition, it should be analyzed whether earnings profiles between

\footnotetext{
${ }^{1}$ Further groups that have to be mentioned are asylum-seekers, refugees and Jewish immigrants from Eastern Europe. In addition, there was a huge resettlement of ethnic Germans from Eastern Europe shortly after World War II.
} 
native Germans and German citizens differ.

There are a couple of studies that focus on earnings prospects for foreigners and immigrants in Germany. ${ }^{2}$ In an early study, Licht and Steiner (1994) test the assimilation hypothesis distinguishing permanent and temporary immigrants in Germany. Their results show that the remuneration of labor market experience is higher for natives than for foreigners and therefore no support for the assimilation hypothesis is established. The studies of Riphahn (2003; 2005) deal with the educational attainment of second generation immigrants. Her results show that the returns to degree are smaller for those groups compared to natives of the same age. The estimates in Riphahn (2002) confirm these findings for the whole population of foreigners in Germany. In line with these results are the findings of Constant and Massey (2003) who analyze earnings of German guestworkers with regard to the segmentation of the labor market. Their results show that immigrants are not capable to translate their human capital into a good first job and therefore the status gap between Germans and guestworkers widened with the time spent in the labor market. A common thing to all these studies is usage of citizenship to identify natives and non-natives. However, the figures from the first paragraph elucidate that there is need to utilize a wider definition than this to capture the economic implications of immigration.

Beyond just analyzing whether differences in earnings profiles occur between the groups described above, we will take a closer look on differences within the group of persons with migration background in a second step. In particular, we try to study whether educational credentials and degrees obtained in Germany and abroad lead to differences in the earnings profiles for the groups in study. Kreyenfeld and Konietzka (2001) investigate a similar question for ethnic German Migrants using cross-section data of the German Socio-Economic Panel (GSOEP) from 1998. Their results show degrees pay-off when employed in a trained occupation and foreign vocational credentials are transferable only in narrowly defined occupation specific labor market segments for ethnic Germans. However, due to the small number of observations and the cross-section nature of the data the findings have to be taken with a grain of salt. In addition, the estimates of Constant and Massey (2003) show that educational attainment in the German system has a strong positive effect on the occupational prestige for guestworkers.

To answer the questions we use the waves 1995 to 2005 from the GSOEP for West Germany. The results show that persons with migration background earn lower wages compared to natives independently of gender or skill-level. Moreover, the earnings profiles of persons with migration background are fairly similar to those of foreigners which implies that values of foreigners could be used as a proxy for the whole sample of people with migration background. A further finding supports this result: the earnings profiles of German citizens provide a good proxy for those of native Germans except for the high-skilled. Hence, using citizenship to approximate natives and non-natives seems to be reasonable when analyzing earnings issues. With regards to the second question (whether degrees obtained abroad or in Germany are valued differently for persons with migration background) we find differences for all skill-levels implying that degrees obtained

\footnotetext{
${ }^{2}$ All the studies cited use data from the German Socio-Economic Panel.
} 
abroad lead to lower earnings prospects. The results for returns to schooling and for returns to university are particularly strong.

The paper is organized as follows: Section 2 discusses the identification of people with migration background in the German population. In Section 3, we present the empirical model used for the estimation of the returns to education. The dataset and selected descriptives are given in Section 4. The results are shown in Section 5. Finally, the last section provides the main conclusions.

\section{Migration Background in Germany}

Analyzing the labor market perspectives of people with migration background requires a thorough definition of this group. However, there is no consensus over this definition in Germany. The main reasons are, in particular, that ethnic Germans possess German citizenship at the time or shortly after immigration and that a number of foreigners who immigrated several decades ago and their descendants were naturalized. Restricting the definition only to foreigners and drawing the comparison of earnings prospects between foreigners and German nationals could be problematic if there are substantial differences between native Germans and German citizens with migration background, because the reference group (German citizens) would be rather heterogeneous.

One possible definition for persons with migration background, also used by the Federal Statistical Office (Statistisches Bundesamt), is the following: People are said to have a migration background if they themselves or their parents are born abroad and they themselves or their parents possess the citizenship of the foreign country or did so in the past. This definition seems to be quite appropriate for the German case as it attributes a migration background to ethnic Germans and their family members. Moreover, it contains naturalized foreigners as well. However, third generation immigrants are not incorporated if their parents possessed German citizenship at birth.

Although migration background relaxes the limitations of using only citizenship to investigate differences between natives and non-natives, the heterogeneity in the group of persons with migration background should also be considered. In the following, we separately analyze the earnings prospects for different groups of persons with migration background. More precisely, we apply two levels of comparison. On the first level, we distinguish between people with migration background and native Germans only. On the second level, we consider three groups within people with migration background: (i) foreigners, i.e. people possessing a citizenship different than German, (ii) people with migration background possessing a German citizenship (but not German resettlers), and (iii) German resettlers. It may be worth noting that German resettlers would belong to category (ii) with respect to the definition of migration background. However, to identify possible differences in the estimates for this particular group, using (ii) and (iii) as 
exclusive concepts seems to make sense. Table 1 summarizes the definition of groups in analysis.

Tab. 1: Definition of Groups in Analysis

\begin{tabular}{ll}
\hline \hline Native Germans $^{\text {a }}$ & $\begin{array}{l}\text { Person and her parents are born in Germany and } \\
\text { possess German citizenship from birth }\end{array}$ \\
\hline $\begin{array}{ll}\text { People with migration background } \\
\text { Foreigner }\end{array}$ & Person possesses citizenship other than German \\
\cline { 2 - 2 } German citizenship & Person was naturalized (but not resettler) \\
\cline { 2 - 3 } German resettlers & $\begin{array}{l}\text { Ethnic Germans, descendants and family mem- } \\
\text { bers who possess German citizenship from the } \\
\text { day of immigration }\end{array}$ \\
\hline \hline
\end{tabular}

${ }^{a}$ German citizens comprise native Germans, naturalized Germans and German resettlers.

Figure 1 provides a graphical illustration of the concept of migration background in Germany with the three distinct sub-groups in use. The whole pie are all persons with migration background in Germany. About 47 percent of those are foreigners. The remaining 53 percent are persons possessing German citizenship; 12 percent are German resettlers (figures for 2005).

Fig. 1: Groups of People with Migration Background

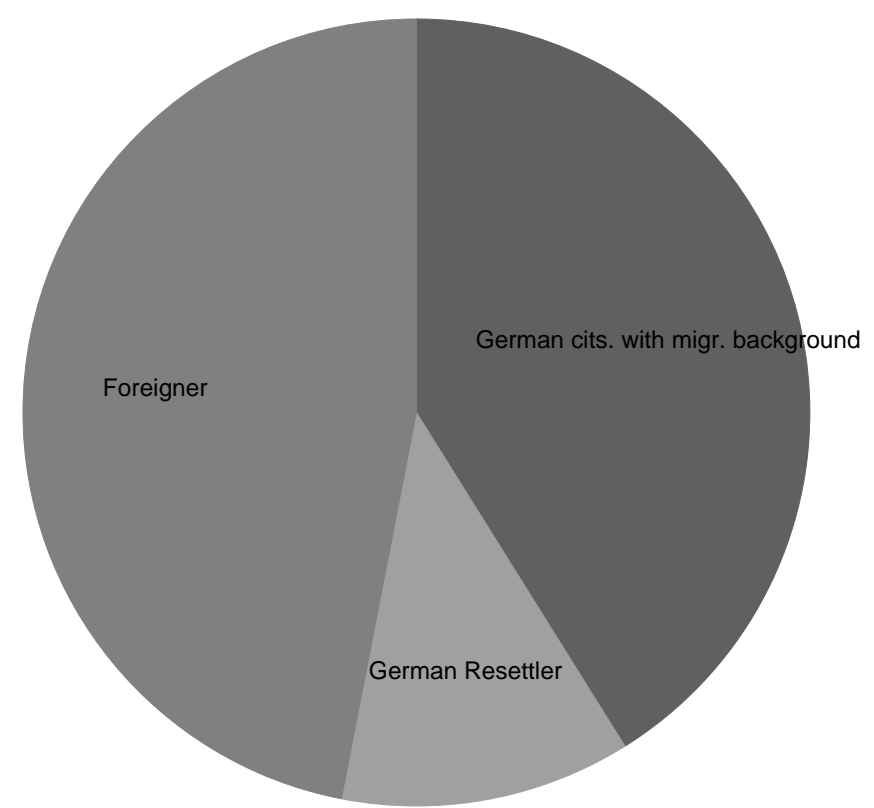

Source: Statistisches Bundesamt (2006), own view

To give some idea on the migration flows over the last decade, Table 2 summarizes these flows in absolute value for selected groups. ${ }^{3}$ As the absolute number of foreign nationals migrating

\footnotetext{
${ }^{3}$ We have also added asylum-seekers in the table. Since asylum-seekers are missing in our database, they are not regarded in the study.
} 
to Germany has decreased (albeit still substantial), the German citizens with migration background, and especially second-generation migrants, are likely to constitute larger shares within the group of persons with migration background, which reinforces the motivation laid out in the introduction. People are said to be first generation immigrants if they have a migration experience, i.e. they themselves immigrated to a host country. Second generation immigrants were born in the host country their parents immigrated to. However, due to data restrictions, i.e. the limited number of observations, we do not distinguish first and second generation immigrants and pool them in one group of persons with migration background. Therefore, we cover first and second generation immigrants in the definition of migration background. ${ }^{4}$

Tab. 2: Immigration and Emigration in Germany for Selected Groups

\begin{tabular}{|c|c|c|c|c|c|c|}
\hline Year & & Total & Germans & $\begin{array}{c}\text { there of } \\
\text { Resettlers }\end{array}$ & Foreigners & $\begin{array}{c}\text { there of } \\
\text { Asylum-Seekers }\end{array}$ \\
\hline \multirow[t]{3}{*}{1993} & Immigration & $1,277,408$ & 287,561 & 217,531 & 989,847 & 322,599 \\
\hline & Emigration & 815,312 & 104,653 & & 710,659 & \\
\hline & Balance & 462,096 & 182,908 & & 279,188 & \\
\hline \multirow[t]{3}{*}{1997} & Immigration & 840,633 & 225,335 & 128,415 & 615,298 & 104,353 \\
\hline & Emigration & 746,969 & 109,903 & & 637,066 & \\
\hline & Balance & 93,664 & 115,432 & & $-21,768$ & \\
\hline \multirow[t]{3}{*}{2001} & Immigration & 879,217 & 193,958 & 86,637 & 685,259 & 88,287 \\
\hline & Emigration & 606,494 & 109,507 & & 496,987 & \\
\hline & Balance & 272,723 & 84,451 & & 188,272 & \\
\hline \multirow[t]{3}{*}{2005} & Immigration & 707,352 & 128,051 & 30,779 & 579,301 & 28,914 \\
\hline & Emigration & 628,399 & 144,815 & & 483,584 & \\
\hline & Balance & 78,953 & $-16,764$ & & 95,717 & \\
\hline
\end{tabular}

Source: Statistisches Bundesamt

\section{Estimating the Earnings Equation for People with Migration Background}

The standard model of estimating the earnings equation was proposed by Mincer (1974). In that model, log earnings are modelled as an additive function of years of a linear schooling term and a quadratic term of experience,

$$
y_{i}=\beta_{0}+\beta_{1} \text { Schooling }_{i}+\beta_{2} \text { Experience }_{i}+\beta_{3} \text { Experience }_{i}^{2}+\varepsilon_{i},
$$

where $y_{i}$ is the logarithm of earnings for individual $i$, Schooling represents the years of completed schooling and Experience is the years of experience after completed schooling, and $\varepsilon$ is the statistical residual. Card (1999) points out the two hypotheses embedded in this specification. First, number of completed years of schooling are the correct measure of education, and second,

\footnotetext{
${ }^{4}$ Analyzing the effects for people with migration background of first and second generation separately is beyond the scope of this paper. For further information on educational attainment of second generation immigrants in Germany, the interested reader is referred to Riphahn (2003; 2005) and Kirsten and Granato (2007).
} 
effects of years of schooling on earnings are proportional. ${ }^{5}$ If both assumptions hold true, $\beta_{1}$ can be interpreted as the internal rate of return to schooling. ${ }^{6}$

However, assuming proportional effects of years of schooling may be to some extent unrealistic in heterogeneous educational systems like in Germany. One can argue the credentials may be more important than years of schooling. This is the so-called "sheepskin effect", which basically means that, for example, one year of university has a different worth than a year of high school. This also holds for the difference between completed school degrees and years of schooling, i.e., leaving high-school without graduation after 13 years has a different value than graduating after this duration. Therefore, a commonly used practice is to augment Eq. (1) by variables accounting for possible non-linearities at certain points in time, which are normally covered by a set of dummies for different types of completed education (the approach that we follow in this paper). For example, in Germany there is a tripartite school system, comprising Hauptschule, Realschule, and Gymnasium. Whereas students of the first and second type remain 9 and 10 years in school, Gymnasium graduation requires 13 years of schooling. ${ }^{7}$ Eligibility for further education in the apprenticeship system or at advanced technical college (Fachhochschule) or university is subject to individual schooling. Students graduating from Gymnasium are eligible for all types of further education; in contrast, graduates from Realschule and Hauptschule are eligible for training in the apprenticeship system only. It usually takes three years to complete further training in the apprenticeship system. University graduation requires, on average, between four and six years of studying. ${ }^{8}$

Assuming proportional effects of schooling (overall or stratified by different types of schools) may be reasonable in a "closed" system, i.e. a particular country. The situation becomes more complicated when aiming at measuring the returns to education for persons educated in different countries and within different systems as pooling degrees obtained in different countries raises the issue of comparability of degrees. Even if contents of education may be comparable in some sense, the skills acquired may be not applicable in the host country for different reasons, e.g., a lack of demand or differences in technology. Nevertheless, the approach of pooling "comparable" degrees is common sense throughout the literature. Another possible approach is to explicitly control whether the person graduated in the country of residence or abroad. However, this stratification results in fewer observations than pooling, which may be at the expense of statistical significance. In the present paper, we follow both approaches, which we discuss in Section 5.

A problem which goes hand in hand with identifying comparable education is the potential experience of individuals. In empirical applications, it is common to use potential rather than actual experience as actual experience is often not observed. Potential experience is calculated

\footnotetext{
${ }^{5}$ Heckman, Lochner, and Todd (2005) find a proportional hypothesis too restrictive.

${ }^{6}$ There are a number of studies that put attention on these assumption, for example, to analyze possible endogeneity of schooling by unobserved variables like motivation or intelligence. However, even more sophisticated methods, e.g., IV, random coefficients etc. do not provide strong advantage in terms of precision of the estimates. Hence, OLS is still a reasonable choice for estimation (see, e.g., Card (1999) for a discussion).

${ }^{7}$ In some of the Federal Laender graduation from Gymnasium requires 12 years of schooling only.

${ }^{8}$ Further information on the German school system can be found at http://www.bildungsserver.de.
} 
as Experience $\equiv$ Age - Schooling $-6 .{ }^{9}$ Hence, it is defined as the potential experience an individual could gather after completed schooling, where the start of schooling is assumed to be at age 6 . Since we do not have the information on the actual duration of schooling and the standard durations for different education types may not necessarily be applicable to immigrants having received education in their home countries, we use age (and age squared) instead of potential experience and interact those with schooling types. In other words, we estimate flexible education type specific wage profiles over the life-cycle.

Finally, besides these modifications further determinants of earnings should be considered in the empirical model. In that sense, it is useful to take account of further socio-demographic variables as well as information on economic activities and regional heterogeneity. Therefore, the empirical analysis below relies on the following model:

$$
\begin{aligned}
\log y_{i t}= & \beta_{0}+\beta_{1} \text { Age }_{i t}+\beta_{2} \text { Age }_{i t}^{2}+\sum_{j=1}^{k} \gamma_{j} \text { skill level }_{j i t}+ \\
& \sum_{j=1}^{k} \kappa_{j} \text { skill level }_{j i t} \times \text { Age }_{i t}+\sum_{j=1}^{k} \lambda_{j} \text { skill level }_{j i t} \times \text { Age }_{i t}^{2}+\alpha \mathbf{X}_{i t}+\nu_{i}+\varepsilon_{i t},
\end{aligned}
$$

where $\beta_{j}, \gamma_{j}, \kappa_{j}$, and $\lambda_{j}$ are the parameters for the returns to $j^{\text {th }}$ education category to be estimated, $\mathbf{X}_{i t}$ is the matrix of covariates to be described below, $\alpha$ is the corresponding vector of parameters, and $\nu_{i}$ and $\varepsilon_{i t}$ are the individual heterogeneity term and the error term respectively. For sake of completeness, $t$ denotes the year.

The matrix $\mathbf{X}$ contains variables with potential impact on the wage level and are also important to explain the situation of persons with migration background in contrast to native Germans. In detail the matrix $\mathbf{X}$ contains economic sectors, indicated by six categories (agriculture, industry, transportation, construction, trading services, social services and health), dummy variable for self-employment, dummy variable for part-time work (as being equal to 1 if the person works less then 30 hours a week). Moreover, we consider fixed year and regional effects (dummies for north, central and south) to take account of possible macroeconomic year-specific changes of the regional economy. ${ }^{10}$ Relevant for the wage position of persons with migration background seems to be time of residence in Germany. With increasing time of residence tenure increases and also migrants should be more equal to native Germans. We use this term and its square (only used for persons with migration background) in our wage equation. Also we tried some other variables asked in the GSOEP like which language is spoken at home - German or the language of origin. This could be good proxy for well integration and also for the possibility to sufficient labor market participation. Unfortunately, concerning this variable we have problems with the number of observations - the variable is only available for half the persons with migration background. Also it should be valuable to control for second generation migrants who are potentially more equal to native Germans since they grow up in the same environment. Unfortunately, the

\footnotetext{
${ }^{9}$ It may be worth noting that schooling refers to time of education out of labor market in our approach.

${ }^{10}$ Considering fixed year effects for macroeconomic conditions differs from calculating cohort effects conditional on year of birth.
} 
low number of observations would decrease precision of the estimates. However, to take gender effects seriously into account, we run the regression in Eq. (2) separately for males and females. ${ }^{11}$ We assume that $\nu_{i}$ is uncorrelated with the explanatory variables and, hence, Eq. (2) can be estimated by the random effect panel method. ${ }^{12}$

\section{Dataset and Selected Descriptives}

\subsection{Dataset}

For the empirical analyses we use information of 11 waves of the German Socio-Economic Panel (GSOEP) from 1995 to $2005 .{ }^{13}$ GSOEP was launched in 1984 and is a wide-ranging representative longitudinal study of private households. It provides information on all household members, consisting of Germans living in all Federal Laender, foreigners, and recent immigrants to Germany. In 2005, there were nearly 12,000 households, and more than 21,000 persons sampled. Several features make the GSOEP preferential to other datasets in Germany for our purpose. The sample is not restricted to persons covered by the social security system, i.e. public officials and self-employed persons are included as well. Moreover, it provides information on wages and the hours worked. It also offers the possibility to observe persons of German origin who immigrated from former Soviet Union and Eastern European states late after 1945. In addition, second generation immigrants could be identified. ${ }^{14}$

The GSOEP offers individual information on country of birth, citizenship and resettler-status amongst others. In addition, a parental identifier is offered if an individual's parents took part in any of the GSOEP-surveys. In these cases, parental information can be added to the individual's information. This allows to define foreigners, people with migration background, and native Germans as follows: Individuals without German citizenship are labelled foreigners. Individuals belonging to the group of migrants are either themselves born abroad or their parents are. Whether a migrant is assigned first or second generation status, depends on his/her own country of birth. First generation status is assigned to migrant individuals born abroad, while second generation status is attributed if born in Germany and parents' have a migration background. Native Germans are neither foreigners, nor people with migration background.

A further advantage is that data are available shortly after the survey has been conducted. A potential disadvantage of the GSOEP concerning migrants is the fact that illegal immigrants and persons living in special entities like asylum camps are not covered in the sample. GSOEP is representative for migrants with the exception of the years between the end of the 1980s and

\footnotetext{
${ }^{11}$ The final specification was due testing of different sets of variables in order to improve precision of the estimates.

${ }^{12}$ This is similar to DeNew and Zimmermann (1993) who also apply random effect methods to estimate the effect of the share of foreign labor on German wages using GSOEP.

${ }^{13}$ For further details on GSOEP see, e.g., Haisken-DeNew and Frick (2005).

${ }^{14}$ As mentioned before, due to limitations in the number of observations we pool first and second generation migrants in the analyses below.
} 
the early 1990s when lots of new migration groups arrived in Germany. The survey expansion in 1994/95 of the GSOEP takes this new development into account and, therefore, our analysis is not affected by the missing representation.

Our study is limited to West Germany, because in East Germany the number of persons with migration background is clearly lower. In addition, the sample is limited to employed persons (dependent as well as self-employed) aged 15 to 65. Further, to reduce the risk of measurement error from extreme values we trim the highest two percent and the lowest two percent observations on hourly wages. The outcome variable (real gross hourly wages) is obtained for all workers including the self-employed by dividing the gross earnings in the month prior to the interview by the reported working hours of the last week that are extrapolated to monthly hours. Wages are deflated using the consumption price index based on the year 2000 to get real consumption wages of comparable purchasing power. ${ }^{15}$

\subsection{Selected Descriptives}

To give a first insight to the situation of people with migration background in our data, Tables 3 and 4 provide means of selected variables for the years 1995 and 2005 distinguishing males and females as well as the groups according to Table 1. The largest group are as expected native Germans. When looking at the people with migration background, it becomes obvious that in 1995 most of those people where foreigners independently of gender. ${ }^{16}$ However, in 2005 the picture is shifted and almost half of the people with migration background belong to one of the other groups. Possible reasons for this development are the naturalization of foreigners and the rising share of second generation immigrants possessing German citizenship.

For males, the average hourly wage is highest for native Germans (13.99 Euro in 1995, 15.70 Euro in 2005) while German resettlers earned the lowest wages (10.64 Euro in 1995, 12.37 Euro in 2005). For all groups except for German citizen with migration background, real wages increased between 1995 and 2005 on average. In that group, wages remained fairly stable. In analogy to males, female native Germans earned the highest wages (10.77 Euro in 1995, 12.19 Euro in 2005) while in 1995 German resettlers (8.62 euro) and in 2005 foreigners (9.72 Euro) earned lowest wages.

\footnotetext{
${ }^{15}$ It should be noted that the reported gross earnings in the month prior to the interview have not been adjusted for end-of-year bonuses, overtime-payments, holiday allowances etc.

${ }^{16}$ This is due to the design of the GSOEP. At this point it may be useful mentioning that the share of people with migration background is clearly higher in the sample than in the population. This is due to overweighting immigrants when the panel was established as well as the 1994/95 expansion to analyze particular questions on socio-economic performance of this group. However, as we carry out separate analyses for native Germans and people with migration background we could refrain from using sampling weights of the observations in this study.
} 
Tab. 3: Means of Selected Characteristics - Males

\begin{tabular}{|c|c|c|c|c|c|c|c|c|c|c|}
\hline \multirow[b]{3}{*}{ Variable } & \multirow{2}{*}{\multicolumn{2}{|c|}{$\begin{array}{c}\text { native } \\
\text { Germans }\end{array}$}} & \multirow{2}{*}{\multicolumn{2}{|c|}{$\begin{array}{c}\text { People } \\
\text { with } \\
\text { migration } \\
\text { background }\end{array}$}} & \multicolumn{6}{|c|}{ thereof: } \\
\hline & & & & & \multicolumn{2}{|c|}{ Foreigners } & \multicolumn{2}{|c|}{\begin{tabular}{|} 
People with \\
migration \\
background \\
and German \\
citizenship
\end{tabular}} & \multicolumn{2}{|c|}{$\begin{array}{l}\text { German } \\
\text { resettler } \\
\text { (ethnic } \\
\text { Germans) }\end{array}$} \\
\hline & 1995 & 2005 & 1995 & 2005 & 1995 & 2005 & 1995 & 2005 & 1995 & 2005 \\
\hline Hourly wage & 13.99 & 15.70 & 11.69 & 13.34 & 11.64 & 13.61 & 13.43 & 13.46 & 10.64 & 12.37 \\
\hline Age & 38.88 & 42.54 & 37.40 & 40.13 & 37.74 & 40.73 & 35.83 & 39.21 & 36.92 & 39.89 \\
\hline Time of Residence in Germany & - & - & 19.73 & 25.86 & 21.79 & 27.77 & 24.84 & 29.03 & 5.58 & 15.40 \\
\hline \multicolumn{11}{|l|}{ Education } \\
\hline No schooling & 0.01 & 0.00 & 0.11 & 0.04 & 0.15 & 0.06 & 0.02 & 0.03 & 0.01 & 0.01 \\
\hline Schooling (regular school system) & 0.12 & 0.11 & 0.17 & 0.15 & 0.18 & 0.14 & 0.16 & 0.18 & 0.12 & 0.12 \\
\hline Schooling (abroad) & 0.01 & 0.00 & 0.19 & 0.09 & 0.22 & 0.14 & 0.01 & 0.05 & 0.15 & 0.04 \\
\hline $\begin{array}{l}\text { Professional training (apprentice- } \\
\text { ship system)/ civil servant }\end{array}$ & 0.65 & 0.61 & 0.22 & 0.43 & 0.20 & 0.43 & 0.56 & 0.41 & 0.08 & 0.45 \\
\hline Professional training (abroad) & 0.01 & 0.01 & 0.23 & 0.04 & 0.20 & 0.04 & 0.07 & 0.03 & 0.51 & 0.04 \\
\hline College or University degree & 0.19 & 0.27 & 0.04 & 0.13 & 0.03 & 0.10 & 0.17 & 0.22 & 0.00 & 0.10 \\
\hline $\begin{array}{l}\text { College or University degree } \\
\text { (abroad) }\end{array}$ & 0.00 & 0.00 & 0.04 & 0.12 & 0.02 & 0.09 & 0.02 & 0.09 & 0.13 & 0.25 \\
\hline Part time work & 0.03 & 0.04 & 0.03 & 0.06 & 0.02 & 0.07 & 0.06 & 0.06 & 0.01 & 0.05 \\
\hline Self-employment & 0.06 & 0.09 & 0.03 & 0.06 & 0.03 & 0.06 & 0.06 & 0.09 & 0.01 & 0.01 \\
\hline \multicolumn{11}{|l|}{ Economic Sectors } \\
\hline Agriculture & 0.00 & 0.02 & 0.00 & 0.02 & 0.00 & 0.02 & 0.00 & 0.02 & 0.00 & 0.03 \\
\hline Industry & 0.24 & 0.32 & 0.39 & 0.55 & 0.40 & 0.53 & 0.31 & 0.49 & 0.40 & 0.68 \\
\hline Transportation & 0.13 & 0.08 & 0.18 & 0.07 & 0.18 & 0.07 & 0.20 & 0.09 & 0.17 & 0.04 \\
\hline Construction & 0.09 & 0.08 & 0.05 & 0.07 & 0.05 & 0.09 & 0.03 & 0.06 & 0.06 & 0.03 \\
\hline Trading services & 0.30 & 0.27 & 0.27 & 0.22 & 0.26 & 0.23 & 0.27 & 0.21 & 0.30 & 0.17 \\
\hline Social services and health & 0.25 & 0.22 & 0.11 & 0.07 & 0.11 & 0.06 & 0.19 & 0.13 & 0.06 & 0.03 \\
\hline \multicolumn{11}{|l|}{ Region $^{a}$} \\
\hline North & 0.22 & 0.20 & 0.15 & 0.15 & 0.11 & 0.12 & 0.16 & 0.13 & 0.31 & 0.27 \\
\hline Center & 0.33 & 0.34 & 0.33 & 0.35 & 0.29 & 0.31 & 0.35 & 0.38 & 0.47 & 0.43 \\
\hline South & 0.44 & 0.47 & 0.53 & 0.49 & 0.59 & 0.57 & 0.50 & 0.49 & 0.22 & 0.30 \\
\hline No. of obs & 1,969 & 3,070 & 974 & 684 & 721 & 358 & 109 & 200 & 144 & 126 \\
\hline
\end{tabular}


Tab. 4: Means of Selected Characteristics - Females

\begin{tabular}{|c|c|c|c|c|c|c|c|c|c|c|}
\hline \multirow[b]{2}{*}{ Variable } & \multicolumn{2}{|c|}{$\begin{array}{c}\text { Native } \\
\text { Germans }\end{array}$} & \multicolumn{2}{|c|}{$\begin{array}{c}\text { People } \\
\text { with } \\
\text { migration } \\
\text { background }\end{array}$} & \multicolumn{2}{|c|}{ Foreigners } & \multicolumn{2}{|c|}{$\begin{array}{l}\text { People with } \\
\text { migration } \\
\text { background } \\
\text { and German } \\
\text { citizenship }\end{array}$} & \multicolumn{2}{|c|}{$\begin{array}{l}\text { German } \\
\text { resettler } \\
\text { (ethnic } \\
\text { Germans) }\end{array}$} \\
\hline & 1995 & 2005 & 1995 & 2005 & 1995 & 2005 & 1995 & 2005 & 1995 & 2005 \\
\hline Hourly wage & 10.77 & 12.19 & 9.06 & 9.92 & 9.03 & 9.72 & 9.69 & 10.31 & 8.62 & 9.80 \\
\hline Age & 37.47 & 41.53 & 37.19 & 40.05 & 36.84 & 40.75 & 36.72 & 38.58 & 39.24 & 40.63 \\
\hline Time of Residence in Germany & - & - & 19.86 & 24.71 & 21.41 & 26.51 & 27.70 & 27.53 & 5.85 & 16.98 \\
\hline \multicolumn{11}{|l|}{ Education } \\
\hline No schooling & 0.01 & 0.00 & 0.17 & 0.05 & 0.22 & 0.09 & 0.03 & 0.01 & 0.06 & 0.01 \\
\hline Schooling (regular school system) & 0.20 & 0.13 & 0.16 & 0.20 & 0.16 & 0.17 & 0.26 & 0.28 & 0.11 & 0.13 \\
\hline Schooling (abroad) & 0.00 & 0.00 & 0.21 & 0.14 & 0.24 & 0.22 & 0.05 & 0.05 & 0.22 & 0.09 \\
\hline $\begin{array}{l}\text { Professional training (apprentice- } \\
\text { ship system)/ civil servant }\end{array}$ & 0.65 & 0.64 & 0.21 & 0.36 & 0.18 & 0.31 & 0.55 & 0.44 & 0.06 & 0.37 \\
\hline Professional training (abroad) & 0.02 & 0.01 & 0.18 & 0.02 & 0.15 & 0.01 & 0.03 & 0.02 & 0.43 & 0.02 \\
\hline College or University degree & 0.12 & 0.21 & 0.03 & 0.13 & 0.03 & 0.09 & 0.07 & 0.16 & 0.00 & 0.17 \\
\hline $\begin{array}{l}\text { College or University degree } \\
\text { (abroad) }\end{array}$ & 0.00 & 0.00 & 0.04 & 0.11 & 0.02 & 0.10 & 0.01 & 0.06 & 0.12 & 0.22 \\
\hline Part time work & 0.34 & 0.42 & 0.26 & 0.39 & 0.23 & 0.40 & 0.32 & 0.39 & 0.38 & 0.36 \\
\hline Self-employment & 0.04 & 0.06 & 0.02 & 0.03 & 0.02 & 0.03 & 0.04 & 0.03 & 0.00 & 0.02 \\
\hline \multicolumn{11}{|l|}{ Economic Sectors } \\
\hline Agriculture & 0.00 & 0.01 & 0.00 & 0.00 & 0.00 & 0.00 & 0.00 & 0.00 & 0.00 & 0.00 \\
\hline Industry & 0.16 & 0.14 & 0.24 & 0.22 & 0.28 & 0.26 & 0.20 & 0.20 & 0.11 & 0.18 \\
\hline Transportation & 0.05 & 0.05 & 0.10 & 0.05 & 0.12 & 0.04 & 0.06 & 0.05 & 0.06 & 0.05 \\
\hline Construction & 0.05 & 0.01 & 0.04 & 0.01 & 0.04 & 0.01 & 0.04 & 0.01 & 0.02 & 0.00 \\
\hline Trading services & 0.29 & 0.37 & 0.16 & 0.39 & 0.16 & 0.40 & 0.19 & 0.39 & 0.17 & 0.35 \\
\hline Social services and health & 0.46 & 0.42 & 0.46 & 0.34 & 0.41 & 0.29 & 0.51 & 0.35 & 0.64 & 0.42 \\
\hline \multicolumn{11}{|l|}{ Region $^{\mathrm{a}}$} \\
\hline North & 0.21 & 0.21 & 0.13 & 0.15 & 0.12 & 0.10 & 0.08 & 0.13 & 0.24 & 0.27 \\
\hline Center & 0.33 & 0.33 & 0.33 & 0.34 & 0.29 & 0.28 & 0.36 & 0.41 & 0.47 & 0.39 \\
\hline South & 0.46 & 0.46 & 0.54 & 0.51 & 0.58 & 0.62 & 0.57 & 0.46 & 0.28 & 0.35 \\
\hline No. of obs & 1,451 & 2,780 & 583 & 573 & 418 & 269 & 76 & 177 & 89 & 127 \\
\hline
\end{tabular}

a North contains the Federal Laender of Schleswig-Holstein, Hamburg, Lower-Saxony, Bremen, and Berlin. Center are the Federal Laender North Rhine-Westphalia, Rhineland-Palatinate, and Saarland. South comprises Hesse, Bavaria, and Baden-Wuerttemberg. 
To give an insight why wages are higher for native Germans we take a look at the composition and the educational attainment of the labor force of the natives and different migrant groups. Native Germans seem on average to be best educated compared to the migration groups. For foreigners and German resettlers there is a general trend toward higher education. For German citizens with migration background the picture is more mixed. While the share of this group with professional training decreased from 56 percent in 1995 to 41 percent in 2005 for males, the fraction of education groups below and above that category increased. The share of people with migration background who completed professional training doubled between 1995 and 2005 . Especially the group of German resettlers experienced a large increase. Resettlers also have a higher share of persons with a college degree compared to native Germans even though these are mostly acquired abroad. The groups where the share of persons who completed education in Germany is higher, earn higher wages. This could mean that degrees obtained in Germany are more valuable. Concerning education levels, males and females have similar composition of the labor force across groups.

On average, native Germans are older than persons with migration background. This could also explain higher wages of the natives as age has a positive influence on wages due to higher productivity caused by higher experience or due to seniority wage payment. Within the persons with migration background, German resettlers show the lowest time of residence (5.58 years in 1995 and 15.4 years in 2005) - and the lowest wages, while it is highest for German citizens with migration background who stayed on average three fourth of their life in Germany. Unlike native Germans, people with migration background, especially German resettlers, are more concentrated in the industry sector. Also, foreigners and German citizens with migration background are over-represented in the south while German resettlers are over-represented in the center of Germany compared to native Germans. Compared to males, females and especially females with migration background are less concentrated in the industry sector but more concentrated in trading services and social services and health. The share of self-employed is highest for native Germans and German citizens with migration background (6 percent in 1995 and 9 percent in 2005) and lowest for German resettlers. 
Tab. 5: Countries of Origin

\begin{tabular}{|c|c|c|c|c|c|c|c|c|c|c|c|c|c|c|c|c|}
\hline & \multicolumn{8}{|c|}{ Females } & \multicolumn{8}{|c|}{ Males } \\
\hline & \multirow{2}{*}{\multicolumn{2}{|c|}{$\begin{array}{c}\text { People } \\
\text { with } \\
\text { migration } \\
\text { background }\end{array}$}} & \multirow{2}{*}{\multicolumn{2}{|c|}{ Foreigners }} & \multicolumn{4}{|c|}{ thereof: } & \multirow{2}{*}{\multicolumn{2}{|c|}{$\begin{array}{c}\text { People } \\
\text { with } \\
\text { migration } \\
\text { background }\end{array}$}} & \multicolumn{6}{|c|}{ thereof: } \\
\hline & & & & & $\begin{array}{l}\text { Peor } \\
\text { mig } \\
\text { back } \\
\text { and } \\
\text { citis }\end{array}$ & $\begin{array}{l}\text { ple with } \\
\text { gration } \\
\text { ground } \\
\text { German } \\
\text { zenship }\end{array}$ & & $\begin{array}{l}\text { erman } \\
\text { settler } \\
\text { thnic } \\
\text { rmans) }\end{array}$ & & & For & eigners & $\begin{array}{l}\text { Peor } \\
\text { mig } \\
\text { back } \\
\text { and } \\
\text { citiz }\end{array}$ & $\begin{array}{l}\text { gle with } \\
\text { ration } \\
\text { ground } \\
\text { German } \\
\text { zenship }\end{array}$ & & $\begin{array}{l}\text { erman } \\
\text { settler } \\
\text { thnic } \\
\text { rmans) }\end{array}$ \\
\hline 1995 & No. & Percent & No. & Percent & No. & Percent & No. & Percent & No. & Percent & No. & Percent & No. & Percent & No. & Percent \\
\hline Other countries & 78 & 13.38 & 36 & 8.61 & 26 & 34.21 & 16 & 17.98 & 83 & 8.52 & 38 & 5.27 & 29 & 26.61 & 16 & 11.11 \\
\hline Germany $^{\mathrm{a}}$ & 87 & 14.92 & 66 & 15.79 & 21 & 27.63 & & & 133 & 13.66 & 92 & 12.76 & 41 & 37.61 & & \\
\hline Turkey & 90 & 15.44 & 89 & 21.29 & 1 & 1.32 & & & 232 & 23.82 & 229 & 31.76 & 3 & 2.75 & & \\
\hline$\left(\right.$ Ex-$^{-}$Yugoslavia $^{\mathrm{b}}$ & 107 & 18.35 & 101 & 24.16 & 6 & 7.89 & & & 142 & 14.58 & 135 & 18.72 & 7 & 6.42 & & \\
\hline Greece & 50 & 8.58 & 49 & 11.72 & 1 & 1.32 & & & 69 & 7.08 & 69 & 9.57 & & & & \\
\hline Italy & 49 & 8.40 & 48 & 11.48 & 1 & 1.32 & & & 110 & 11.29 & 107 & 14.84 & 3 & 2.75 & & \\
\hline Spain & 22 & 3.77 & 22 & 5.26 & & & & & 44 & 4.52 & 44 & 6.10 & & & & \\
\hline Poland & 48 & 8.23 & 6 & 1.44 & 7 & 9.21 & 35 & 39.33 & 75 & 7.70 & 7 & 0.97 & 8 & 7.34 & 60 & 41.67 \\
\hline $\mathrm{CIS}^{\mathrm{c}}$ & 52 & 8.92 & 1 & 0.24 & 13 & 17.11 & 38 & 42.70 & 86 & 8.83 & & & 18 & 16.51 & 68 & 47.22 \\
\hline \multicolumn{17}{|l|}{2005} \\
\hline Other countries & 119 & 20.77 & 55 & 20.45 & 47 & 26.55 & 17 & 13.39 & 108 & 15.79 & 47 & 13.13 & 45 & 22.50 & 16 & 12.70 \\
\hline Germany $^{\mathrm{a}}$ & 102 & 17.80 & 46 & 17.10 & 55 & 31.07 & 1 & 0.79 & 137 & 20.03 & 65 & 18.16 & 71 & 35.50 & 1 & 0.79 \\
\hline Turkey & 63 & 10.99 & 49 & 18.22 & 14 & 7.91 & & & 126 & 18.42 & 94 & 26.26 & 32 & 16.00 & & \\
\hline$\left(\right.$ Ex-$\left.^{-}\right)$Yugoslavia $^{\mathrm{b}}$ & 61 & 10.65 & 50 & 18.59 & 8 & 4.52 & 3 & 2.36 & 64 & 9.36 & 53 & 14.80 & 11 & 5.50 & & \\
\hline Greece & 18 & 3.14 & 17 & 6.32 & 1 & 0.56 & & & 25 & 3.65 & 24 & 6.70 & 1 & 0.50 & & \\
\hline Italy & 37 & 6.46 & 35 & 13.01 & 2 & 1.13 & & & 55 & 8.04 & 51 & 14.25 & 4 & 2.00 & & \\
\hline Spain & 6 & 1.05 & 6 & 2.23 & & & & & 17 & 2.49 & 17 & 4.75 & & & & \\
\hline Poland & 71 & 12.39 & 4 & 1.49 & 25 & 14.12 & 42 & 33.07 & 52 & 7.60 & 2 & 0.56 & 11 & 5.50 & 39 & 30.95 \\
\hline CIS $^{c}$ & 96 & 16.75 & 7 & 2.60 & 25 & 14.12 & 64 & 50.39 & 100 & 14.62 & 5 & 1.40 & 25 & 12.50 & 70 & 55.56 \\
\hline
\end{tabular}

${ }^{a}$ People with migration background who are born in Germany are descendants of immigrants from foreign countries.

b (Ex-)Yugoslavia refers to the countries Bosnia and Herzegovina, Croatia, Kosovo, Macedonia, Slovenia, and Serbia and Montenegro (Yugoslavia). ${ }^{c}$ CIS denotes the Commonwealth of Independent States, i.e. Armenia, Azerbaijan, Georgian Republic, Kazakhstan, Kyrgystan, Moldova, Republic of Belarus, Russia, Tajikistan, Turkmenistan, Ukraina, and Uzbekistan. 
Table 5 describes countries of origin for males and females with migration background (and for the three subgroups: foreigners, German citizens with migration background and German resettlers) for the years 1995 and 2005. The main fraction of persons with migration background comes from traditional guest-worker countries like Turkey, Italy and other South-European countries. German resettlers mainly arrived from CIS and Poland. Concerning gender shares of the migration force it is should be noted that for migrants with Turkish ancestry the share of males is higher than the share of females (23.82 and 15.44 in 1995 and 18.42 and 10.99 in 2005). For the migrants with (Ex-)Yugoslavian ancestry the share of females was higher in 1995 but equalled with the share of males by 2005. In contrast the shares of males and females for persons with Polish ancestry were almost equal in 1995, but by 2005 female share is higher than the share of males.

\section{Results}

\subsection{Earnings Prospects for Persons with Migration Background}

The vast majority of the literature on economics of immigration in Germany focusses on citizenship to distinguish natives and non-natives. ${ }^{17}$ However, in regards to the substantially larger number of persons with migration background compared to people possessing a foreign citizenship, there may be doubts on the transferability of the results from the studies based on citizenship to the population of persons with migration background. In that context, one has to bear in mind that the reference group could be contaminated by naturalized immigrants. ${ }^{18}$ Hence, the first issue we want to analyze is how comparable are the earnings of persons with migration background and foreigners. To answer this question, we construct the wage profiles with $95 \%$ confidence limits (shaded grey) for the average individual (using the group-means of the explanatory variables) aged 25 to 60 with a distinction for gender for the following groups: persons with migration background compared to native Germans (Fig. 2) and persons with migration background compared to foreigners (Fig. 3). ${ }^{19}$ Moreover, we distinguish three skill groups in the graphs. We define the low-skilled as persons belonging to either category "no schooling", "schooling (regular school system)" or "schooling (non-regular school or abroad)". Persons coded "professional training (apprenticeship system)/civil servant" or "other professional training" are defined as medium-skilled in our analysis. The high-skilled are defined as having "college or university degree" or "college or university degree (abroad)".

\footnotetext{
${ }^{17}$ See, e.g., Gang and Zimmermann (2000), Dustmann and van Soest (2002), Riphahn (2005), or Fertig and Schmidt (2001).

18 Although naturalized immigrants possess all rights and duties as every German citizen, their economic integration may differ due to language difficulties, different education or cultural differences for instance.

${ }^{19}$ What should be beard in mind is that native Germans are a sub-group of German citizens usually employed to study differences between foreigners and Germans. The age interval was chosen to exclude apprenticeship system/university participation on the left side and early retirement issues on the right side. The profiles are constructed based on the estimation results presented in Tables A.1 and A.2. For the sake of completeness, Fig. A.1 in the Appendix compares the earnings prospects of foreigners to that of native Germans.
} 
Fig. 2: Wage Profiles: Native Germans vs. Persons with Migration Background Low-skilled

Males

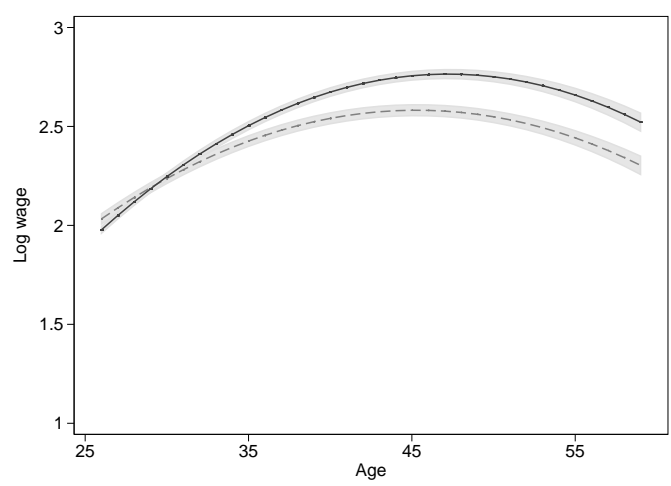

Females

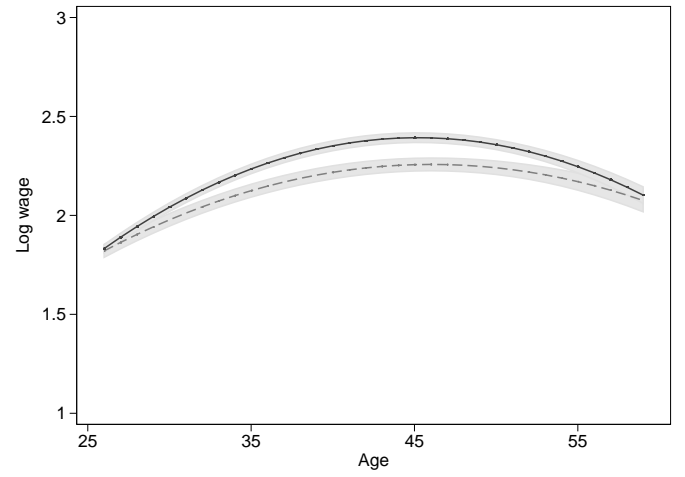

Medium-skilled

Males

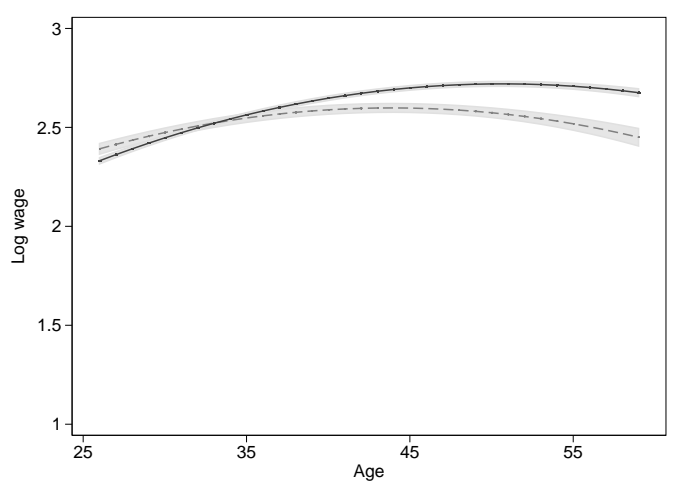

Females

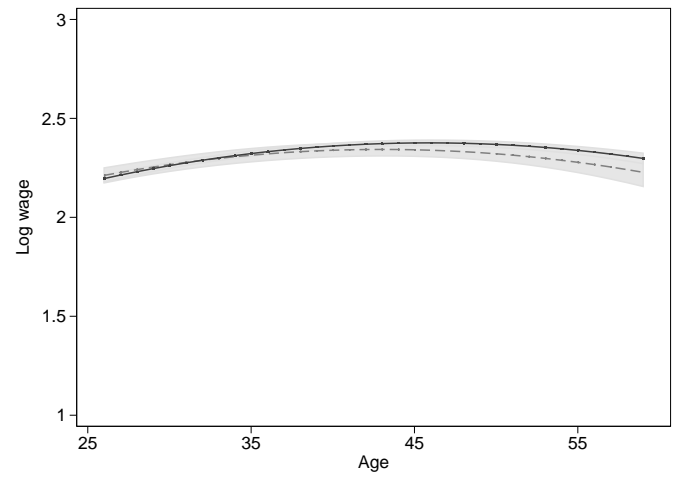

High-skilled

Males

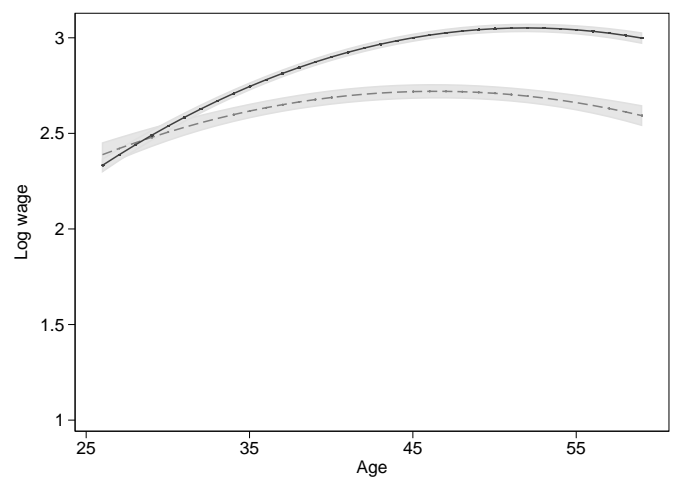

Females

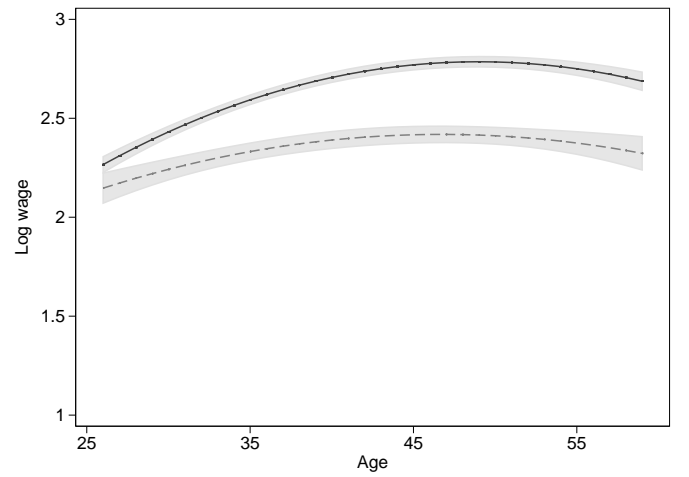

Solid line (-) refers to native Germans, dashed line (- -) refers to persons with migration background. $95 \%$ confidence limits are shaded grey.

It becomes evident from Fig. 2 that persons with migration background have significantly lower earnings prospects than native Germans over the life-cycle independently of gender and skill- 
Fig. 3: Wage Profiles: Persons with Migration Background vs. Foreigners Low-skilled

Males

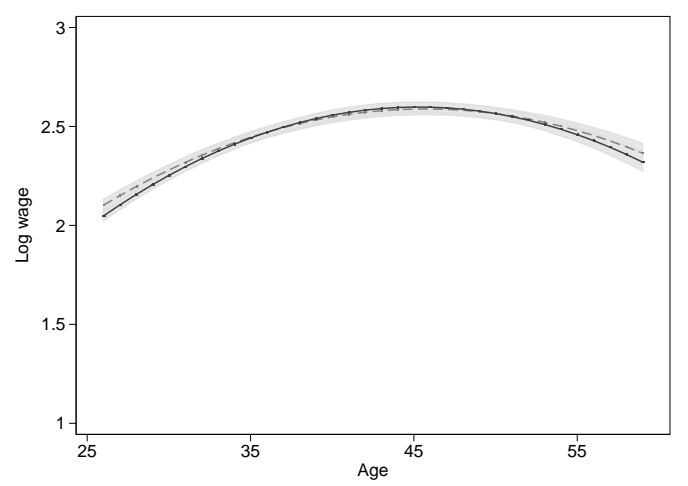

Females

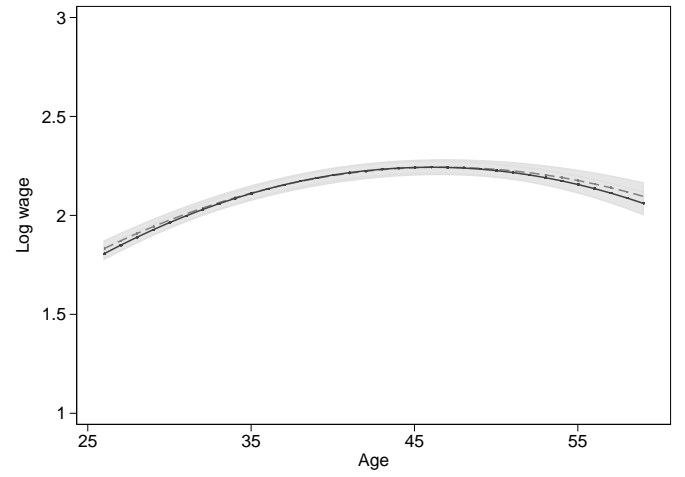

Medium-skilled

Males

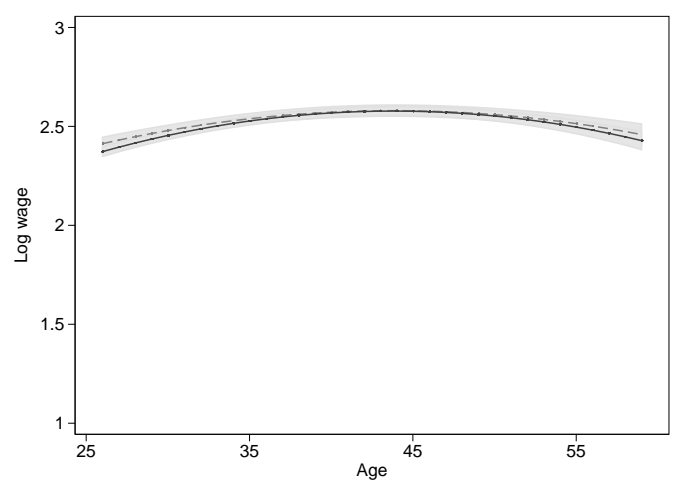

Females

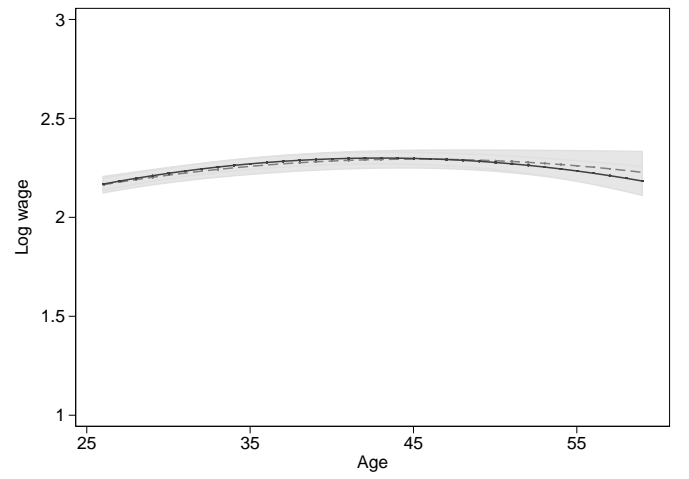

High-skilled

Males

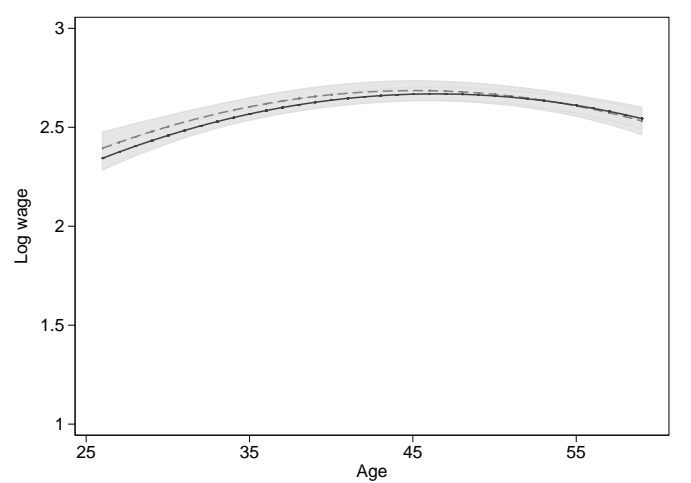

Females

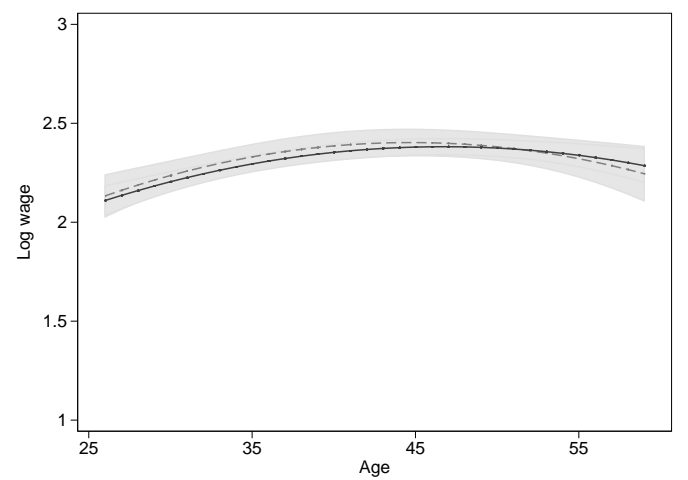

Solid line (-) refers to persons with migration background, dashed line $(--)$ refers to foreigners. $95 \%$ confidence limits are shaded grey.

level. These differences are particularly strong for the low- and the high-skilled. In contrast to that the differences for the medium-skilled are clearly smaller; for females no differences could 
be established. A possible explanation for the estimated differences within the skill-groups are differences in composition of persons with migration background and native Germans. For example, persons with migration background work more often in industry and are located in the south (see Tables 3 and 4). Moreover, the longer persons live in Germany (variable time of residence), the higher are the earnings prospects.

Given the differences between persons with migration background and native Germans, the question is how people with migration background differ from foreigners. Fig. 3 compares the wage profile of the average foreigner to the average individual with migration background. The wage profiles of both groups are very similar in all six groups displayed. Neither gender nor skill differences could be established between foreigners and persons with migration background. The similarities in the earnings between both groups indicate that when analyzing wages one could possibly pool both groups into one. Moreover, it also implies that we could generalize earnings prospects of foreigners to be valid for the whole group of persons with migration background.

The second issue we want to analyze in this context is the possible contamination of the reference group. The wage profile of the average native German could possibly differ from that of the average German citizen since the latter contains in addition feature of naturalized immigrants. In analogy to the figures shown so far, we study this question by comparison of the wage profiles with respect to gender and the three different skill levels (Fig. 4). ${ }^{20}$ Except for the high-skilled, the wage profiles of natives do not differ from those of German citizen. Hence, the group of German citizens provide a reasonable proxy for native Germans when analyzing earnings of lowand medium-skilled individuals in West Germany. However, for the high-skilled the graphs point towards a slightly downward biased earnings profile for males and females of German citizens compared to native Germans. Although not strong, this difference is significant. Thus, using citizens instead of natives to shed light on native-non-native issues could lead to wrong political implications. This difference is determined mainly be high-qualified German resettlers who are often employed in jobs that do not match their formal qualification.

The results of Fig. 4 compare the earnings profiles of native Germans to all German citizens, i.e. the sum of native Germans, naturalized immigrants as well as German resettlers. Although there are no overall differences observable between those groups (except for the high-skilled), it may be interesting to know whether those naturalized persons are more similar to native Germans or to foreigners. To study this issue, Fig. 5 and 6 compare the earnings profiles of the average native German and of the average foreigner to the average naturalized German (excluding German resettlers). The graphs of Fig. 5 clarify that except for low-skilled females earnings prospects of naturalized Germans differ from that of natives. For low- and medium-skilled males, the gap in the earnings profiles starts widening in the beginning 40ies. In contrast to that, for high-skilled males (and females) the same picture could be revealed in the mid 30ies already. Fig. 6 provides the analogous estimates for foreigners compared to naturalized Germans. It is evident from the graph that earnings prospects of foreigners are not significantly different from those of German

\footnotetext{
${ }^{20}$ The estimation results for German citizen are available on request by the authors.
} 
Fig. 4: Wage Profiles: Native Germans vs. German Citizens

Low-skilled

Males

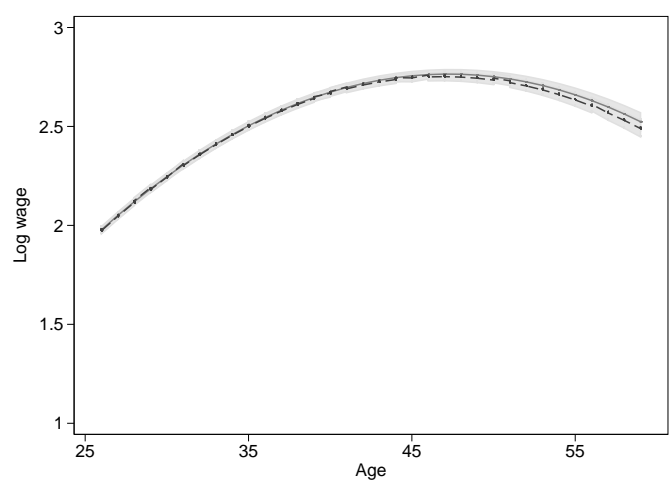

Females

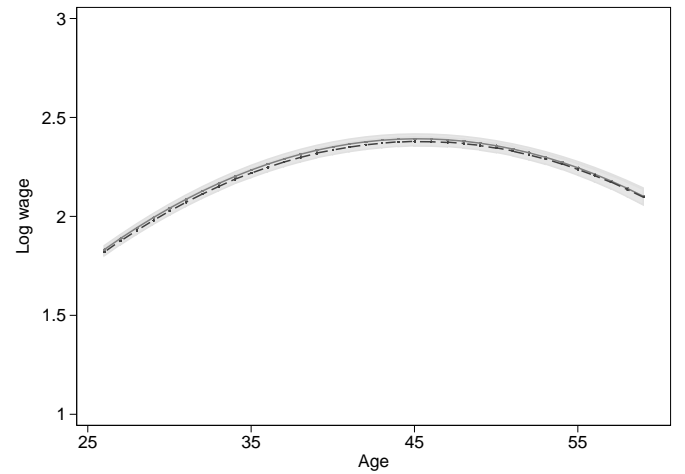

Medium-skilled

Males

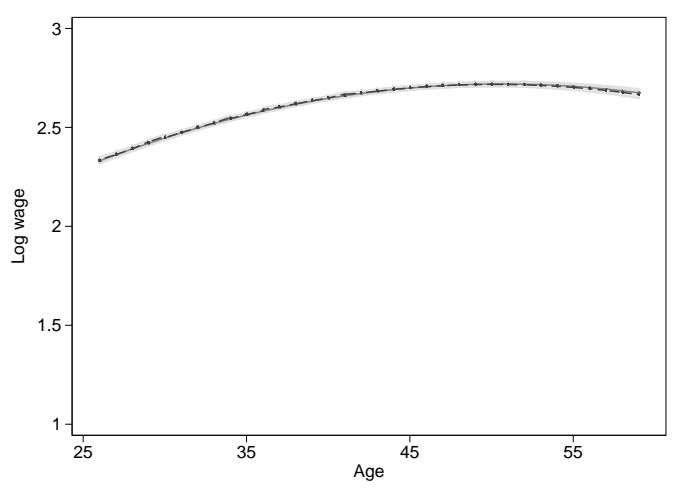

Females

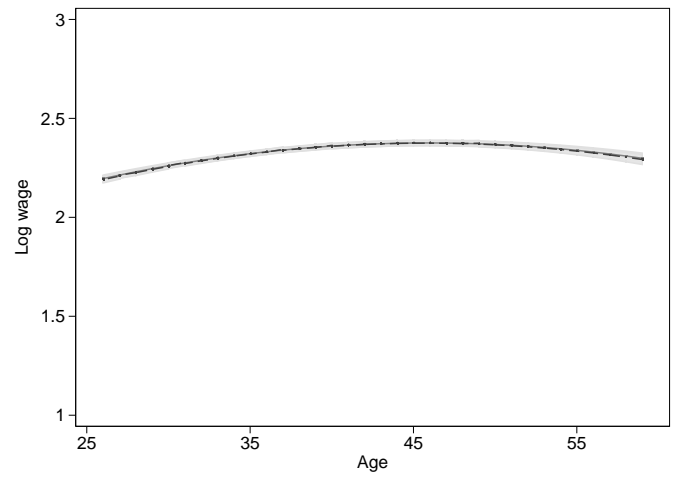

High-skilled

Males

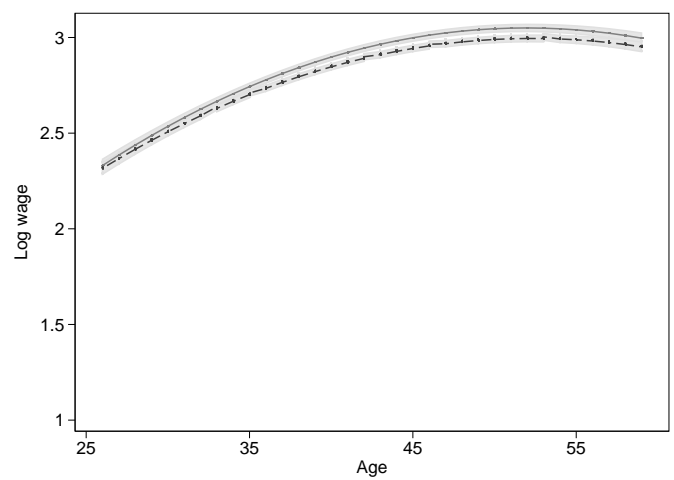

Females

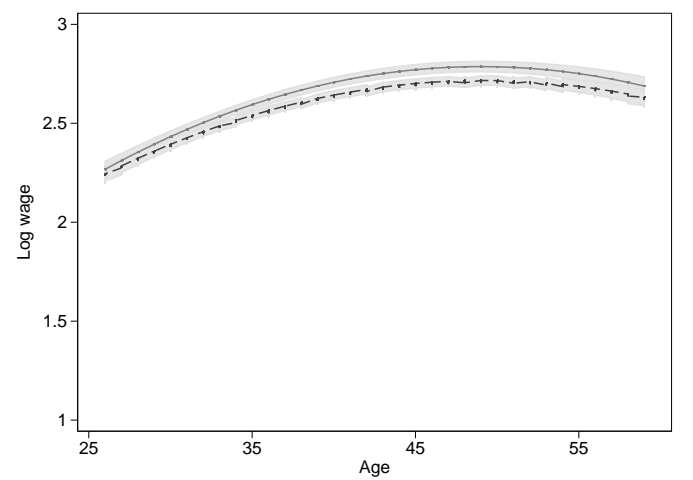

Solid line (-) refers to native Germans, dashed line (- - ) refers to German citizens. $95 \%$ confidence limits are shaded grey.

citizens with migration background (except for high-skilled males at the age between about 40 to 53). These similarities in earnings between foreigners and German citizens with migration 
Fig. 5: Wage Profiles: Native Germans vs. German Citizens with Migration Background Low-skilled

Males

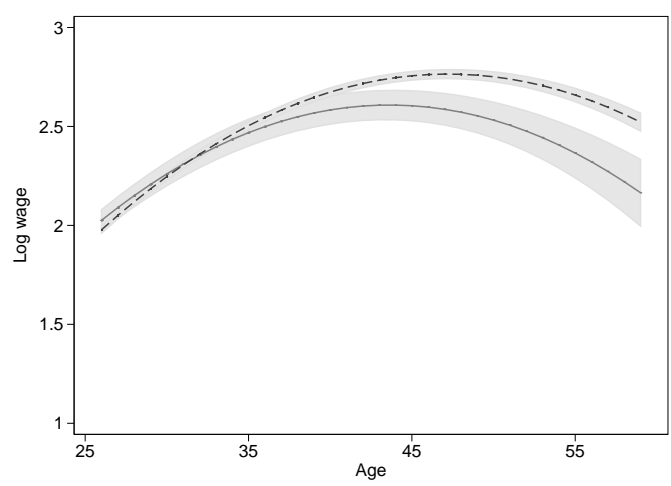

Females

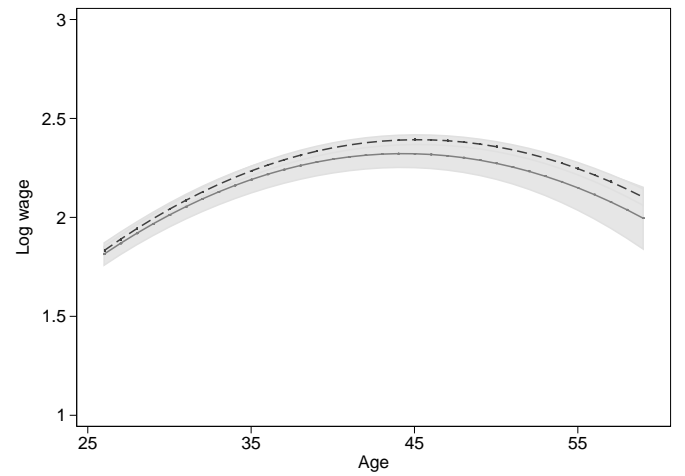

Medium-skilled

Males

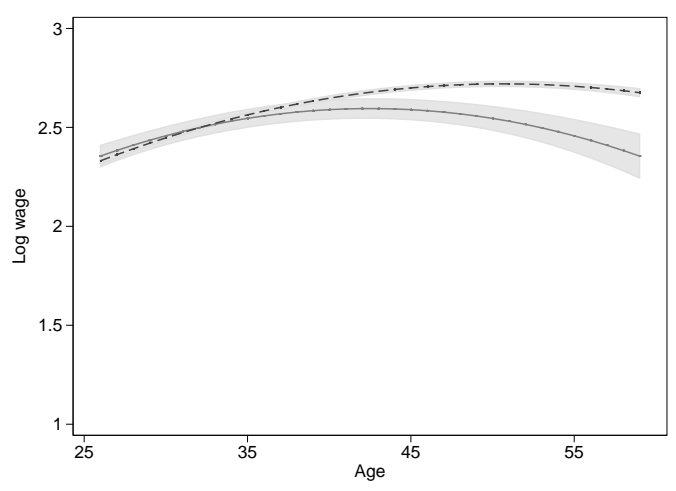

Females

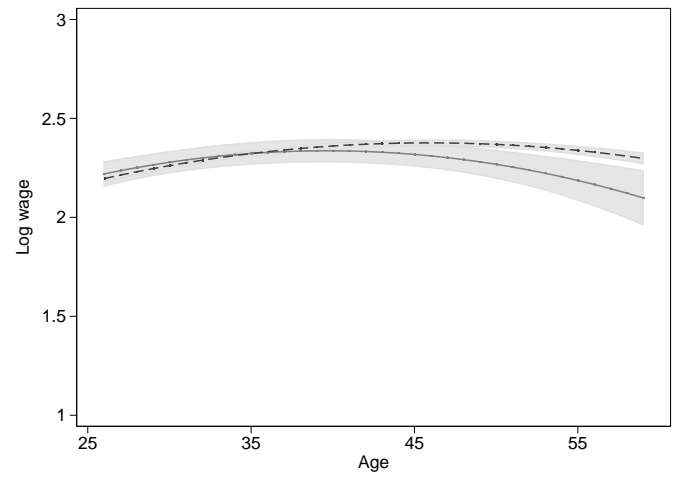

High-skilled

Males

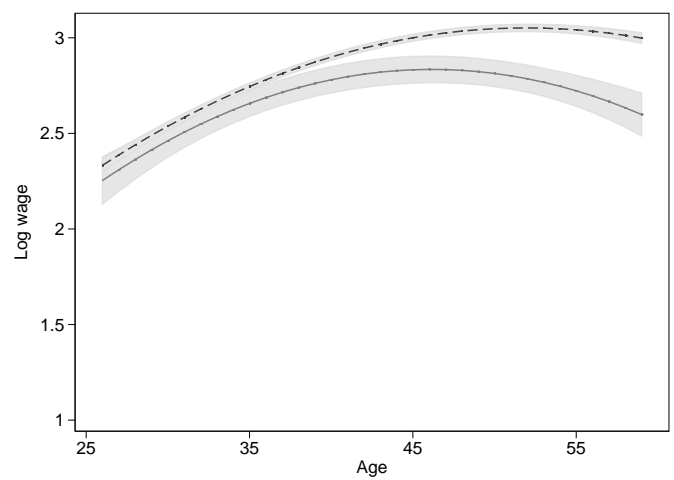

Females

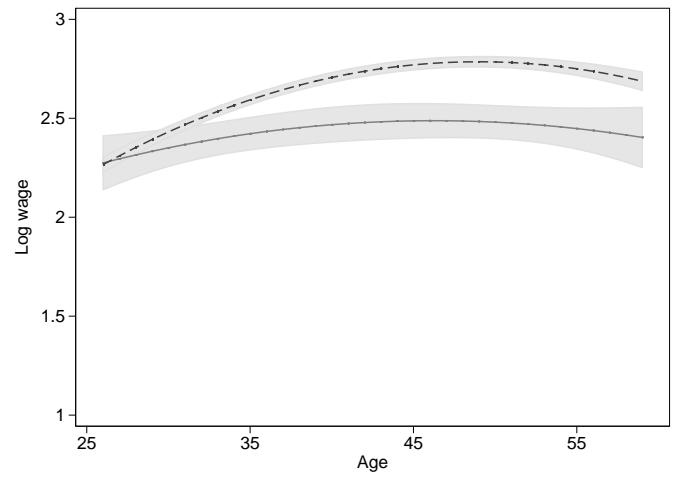

Solid line (-) refers to German citizens with migration background, dashed line (- -) refers to native Germans. 95\% confidence limits are shaded grey.

background indicate that when analyzing wages we could possibly pool foreigners and German citizens with migration background into one group. 
Fig. 6: Wage profiles: Foreigners vs. German Citizens with Migration Background Low-skilled

Males

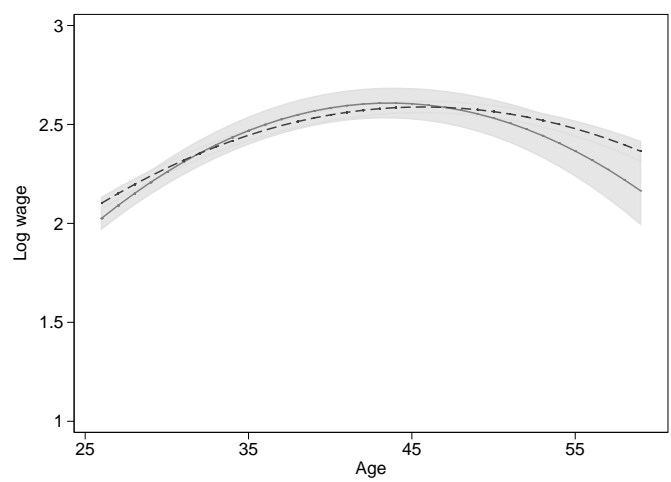

Females

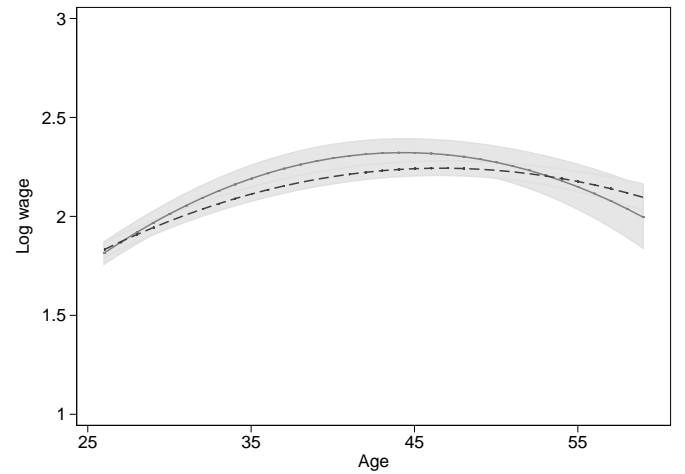

Medium-skilled

Males

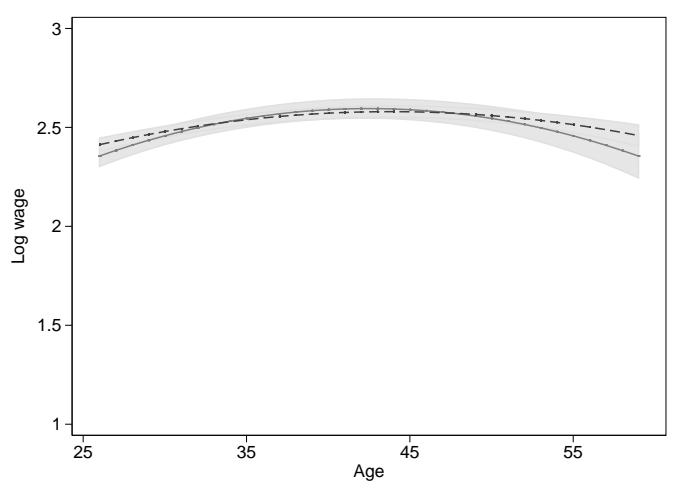

Females

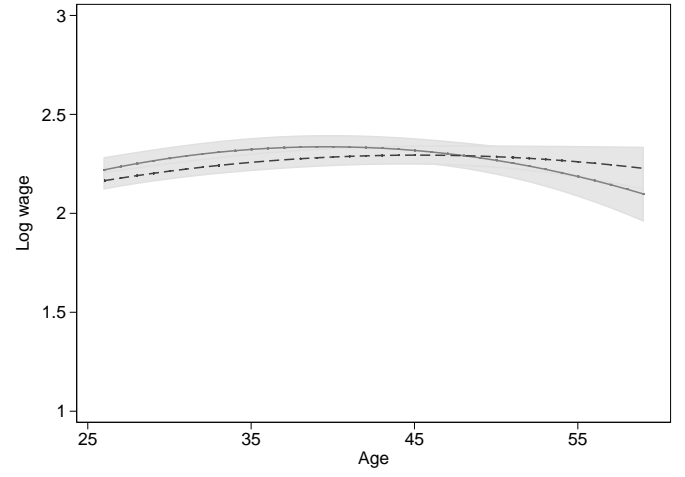

High-skilled

Males

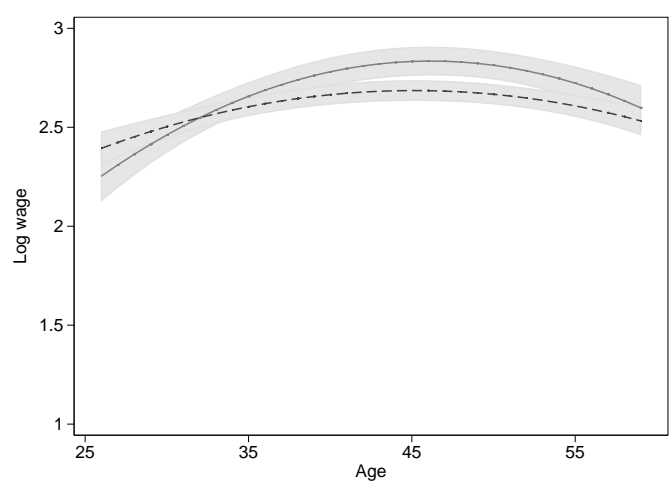

Females

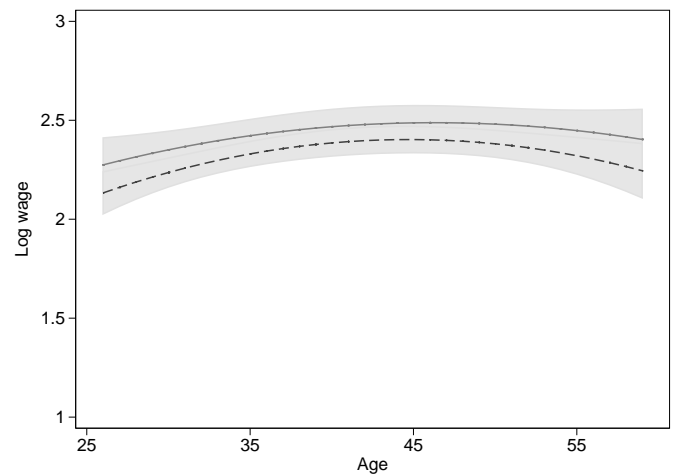

Solid line (-) refers to German citizens with migration background, dashed line (- -) refers to foreigners. $95 \%$ confidence limits are shaded grey.

To test the sensitivity of the estimates we carried out estimations using the panel for the years 2000 to 2005 only. Fig. A.2 and A.3 in the appendix provide the earnings profiles for native 
Germans vs. German citizens and for foreigners vs. German citizens with migration background. Again, we find no differences between natives and citizens for low- and medium-skilled individuals. For high-skilled, there are some minor statistical significant differences for females. The comparison of the wage profiles for foreigners and German citizens with migration background results in a fairly similar picture, too. Unfortunately, no significant differences could be established between the groups. However, the lower number of observations in the reduced panel coincide with a larger variance of the estimates. Hence, although estimates are not totally robust, the alternative estimations tend to support our findings based on the 11 waves.

Tab. 6: Differences in Returns to Education for Selected Age Cohorts ${ }^{\text {a }}$

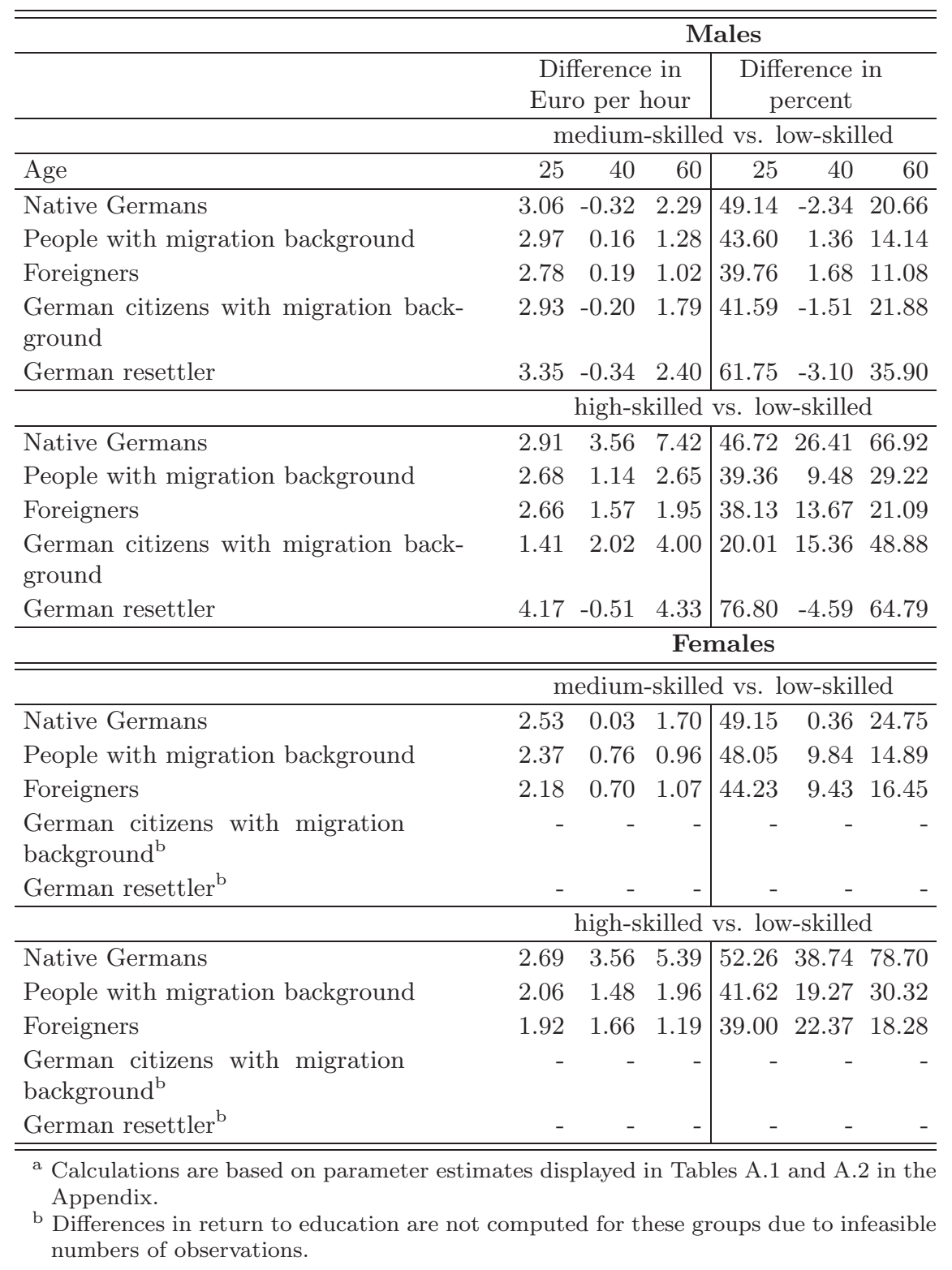

Finally, Table 6 presents the wage differences between skill categories within the groups under study for selected ages (25, 40 and 60 years) separately by gender. The upper panels provide the difference between medium- and low-skilled workers, the lower the difference between high- 
and low-skilled individuals. It becomes clear from the calculations that there are substantial skill-wage differences in particular for younger and older people. In summary, the findings show that for native Germans and naturalized immigrants the wage gap between high- and low-skilled increases with age, whereas the gap between medium- and low-skilled decreases up to certain age and then increases again. ${ }^{21}$

Our result differ from findings of, e.g., Chiswick (1978) where immigrants experience rising earnings profiles that exceed comparable native Americans later in the life-cycle. Chiswick argues that this is due to positive selection of the migration force concerning motivation and unobserved skills. Based on his empirical findings for white male immigrants, he formulated the assimilation hypothesis. With respect to our findings, no such assimilation could be established. Does Germany attract a more negatively selected sample of immigrants than the US? The answer should be no, since one has to take into account possible cohort effects (see Borjas (1985)). If composition of cohorts change the finding of assimilation might be a statistical artefact in the US since older cohorts (arriving before the 1950s) were mostly well-educated from Western Europe, whereas in later decades the majority of immigrants arrived developing countries. In contrast, as explained above, immigration to Germany was quite homogeneous with respects to skills of the migrants.

\subsection{Education in Germany vs. Education Abroad}

From the last section it is obvious that earnings prospects of persons with migration background do clearly differ from that of native Germans independently of the skill-level. One possible reason for that finding could be that persons with migration background are less able to transfer their human capital (measured by the degree obtained) into good jobs of that the values of human capital differ with regards to educational attainment in Germany or abroad. ${ }^{22}$

Considering the figures from Tables 3 and 4 again, we see that in 1995 about one fifths of the persons with migration background attended a school abroad, whereas in 2005 it was only about 9 (males) to 14 percent (females). Vice versa, the number or immigrant people attending school in Germany increased during the same period. A similar, but even stronger development could

\footnotetext{
${ }^{21}$ One issue elided in the text is the gap between males and females. In line with the typical literature on that topic, the results throughout all estimations establish lower earnings for women compared to men. However, as there are no substantial differences within each gender for the migrant and non-migrants groups, we refrain from a self-contained discussion.

${ }^{22}$ There is some evidence for Germany that educational attainment differs substantially between the native population and persons with migration background. Schnepf (2004) compares a number of surveys on educational performance for selected OECD countries participating in PISA, TIMSS, and PIRLS. She finds that differences in performance between native and migrant students are particularly high in Germany. The results of Schnepf (2004) are in line with the findings of Ammermüller (2007). See also OECD (2006). Moreover, the educational level of native Germans increases stronger over time than for the immigrants (Riphahn, 2005). In line with this, the share of foreigners in high-skilled labor amounts to 3.3 percent in 2000 reported by Bauer and Kunze (2005). In addition, Gang and Zimmermann (2000) argue that the longer the immigrants stay in Germany, the more likely they attain better education. (PISA is the acronym for "Programme for International Student Assessment", TIMSS stands for "Third International Mathematics and Science Study", and PIRLS refers to "Progress in International Reading Literacy Study".)
} 
be observed with respect to professional training; whereas in 1995 the share of people possessing a degree from abroad was almost similar to that of persons who obtained the degree in Germany (within the group of persons with migration background) ${ }^{23}$ In 2005 only a minority of people passed the tests abroad (4 percent of males and 2 percent of females). In the same time, the number of people trained in Germany rose thoroughly (up to 43 percent of males and 36 of females). Despite this, the picture for university and college degrees is the other way round. Here, the number of people possessing a foreign degree increased during the years 1995 and 2005.

To analyze whether degrees or credentials are valued differently depending on place of obtainment, we estimate the returns to degree for persons with migration background with explicit consideration whether the degree was obtained in Germany or abroad and compare the earnings profiles descriptively. Fig. 7 displays the wage profiles for the average person with migration background distinguishing schooling, professional training and university abroad or in Germany. Although comparison of the single lines does not have a causal meaning, the descriptive evidence from an eye-ball test is unambiguous. Except for females with a completed professional training, degrees obtained abroad lead to lower earnings profiles for people with migration background compared to when obtained in Germany. Persons with migration background attending schooling in Germany are better off in terms of earnings between about 36/35 and 54/51 years of age (males/females). In contrast, people possessing a university degree from Germany have higher returns over the whole life-cycle.

\section{Conclusion}

The share of persons with migration background in Germany's population has increased during the past decades. A considerable number of these people possesses German citizenship for a number of reasons. The main reasons are, on the one hand, that former guestworkers, their family members and descendants chose to become naturalized after they decided to stay permanently in Germany. On the other hand, a large number of ethnic Germans and family members returned from Eastern Europe and received German citizenship at the date of (re-)immigration. Thus, in 2005 , about $9 \%$ of Germany's population were foreigners, but about $19 \%$ people with migration background.

Many studies use citizenship to analyze economic issues of immigration. However, in light of the true situation this approach may be problematic as more than half of the population with migration background is neglected and, moreover, the effects for the reference group (native Germans) may be contaminated by that of naturalized and ethnic Germans who possibly differ from natives. In this paper, we utilize a wider concept of migration background to analyze earnings prospects of immigrants in Germany. To give evidence on possible bias when using citizenship

\footnotetext{
${ }^{23}$ In numbers this means 22(21) percent of males (females) were trained in Germany and 23(18) percent were trained abroad)
} 
Fig. 7: Wage Profiles of Degrees obtained in Host and Home Country

Returns to School Degree

Males

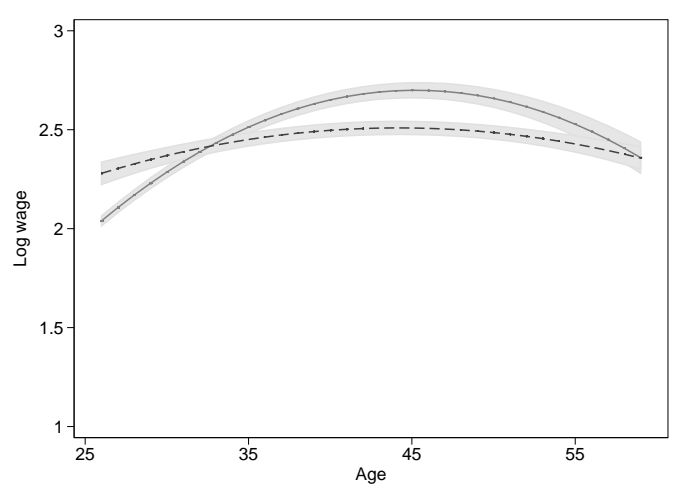

Females

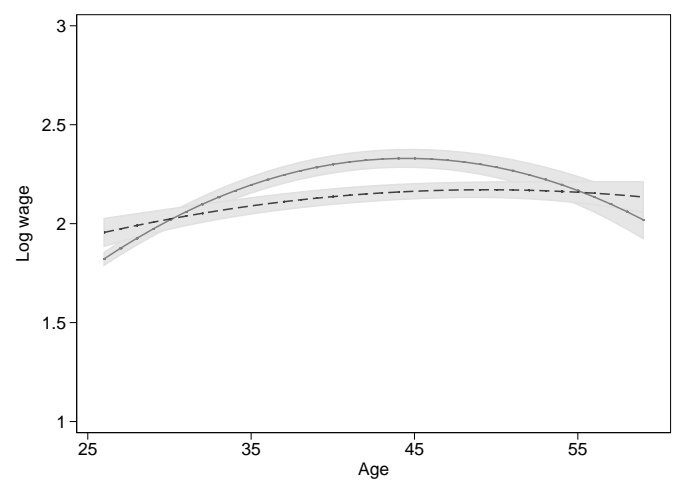

Returns to Professional Training

Males

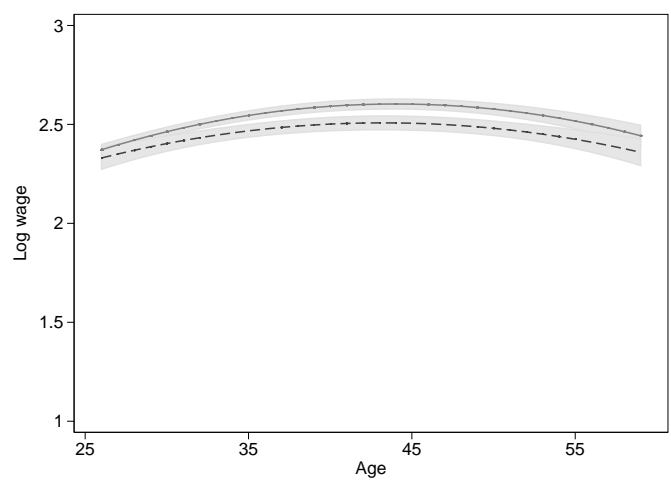

Females

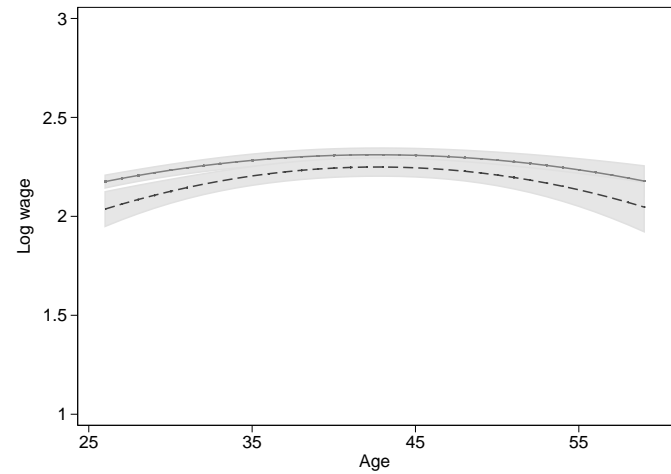

Returns to University Degree

Males

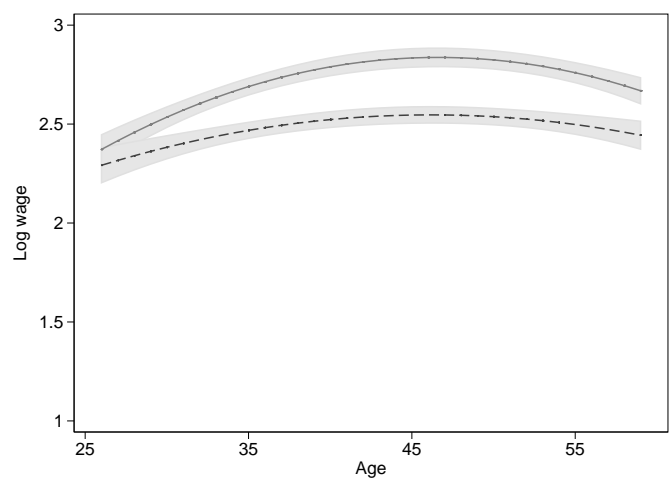

Females

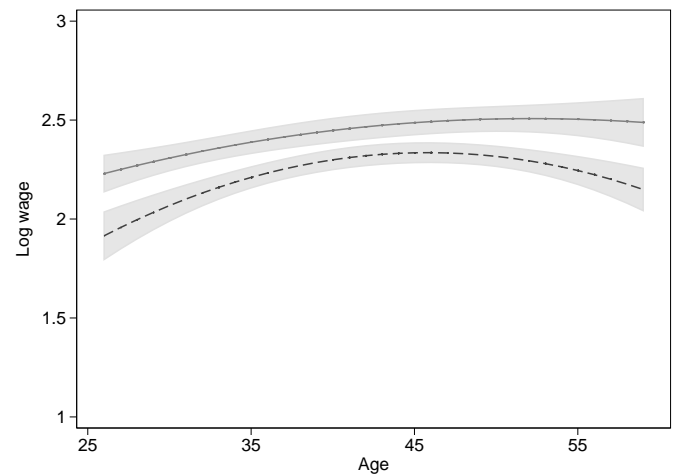

Solid line (-) represents degrees obtained in Germany, dashed line $(--)$ represents degrees obtained abroad.

instead of background, we compare the estimates of persons with migration background to those of foreigners. Moreover, to see how strong a potential contamination affects analyzes of earnings, we compare earnings profiles of native Germans with that of German citizens. Our empirical analysis is based on data from the German Socio-Economic Panel using the waves 1995 to 2005 for West Germany. To consider gender- as well as skill-heterogeneity explicitly, all estimations 
are carried out separately for males and females and for three skill-groups (low-, medium- and high-skilled).

The results show that persons with migration background have on average lower earnings prospects compared to native Germans independently of skill-level or gender. Compared to foreigners, their expected wages are fairly similar except for the high-skilled. A further finding is that earnings prospects for native Germans do not differ much from those of German citizens. Hence, the potential contamination of the reference groups is not that problematic. Therefore, using citizenship to approximate natives and non-natives when analyzing earnings issues seems to be reasonable. However, the exception for high-skilled people has to be regarded.

A further issue of the paper deals with the question whether degrees obtained abroad valued differently from degrees obtained in Germany for persons with migration background. For low- and, in particular, medium-skilled degrees the number of people trained in Germany has increased significantly. Despite this, the number of university credentials obtained abroad has risen. Comparison of the earnings profiles affirms higher earnings to educational attainment in Germany than education abroad independently of gender and skill level. 


\section{References}

Altonji, J. G., and R. M. Blank (1999): "Race and Gender in the Labor Market," in Handbook of Labor Economics, ed. by O. Ashenfelter, and D. Card, vol. 3C, chap. 48, pp. 3143-3259. Elsevier Science B.V., Amsterdam.

Ammermüller, A. (2007): "Poor Background or Low Returns? Why Immigrant Students in Germany Perform so Poorly in PISA," Education Economics, forthcoming.

Bauer, T., And A. Kunze (2005): "The Demand for High-Skilled Workers and Immigration Policy," Brussels Economic Review, 47(1), 57-75.

Borjas, G. J. (1985): "Assimilation, Changes in Cohort Quality, and the Earnings of Immigrants," Journal of Labor Economics, 3(4), 463-489.

CARD, D. (1999): "The Causal Effect of Education on Earnings," in Handbook of Labor Economics, ed. by O. Ashenfelter, and D. Card, vol. 3A, chap. 30, pp. 1802-1863. Elsevier Science B.V., Amsterdam.

Chiswick, B. R. (1978): "The Effect of Americanization on the Earnings of Foreign-born Men," Journal of Political Economy, 86(5), 897-921.

Constant, A., And D. S. Massey (2003): "Labor Market Segmentation and the Earnings of German Guestworkers," Discussion Paper No. 774, IZA.

DeNew, J., And K. F. Zimmermann (1993): "Native wage impacts of foreign labor: a random effects panel analysis," Journal of Population Economics, 7, 177-192.

Dustmann, C., And A. VAn Soest (2002): "Language and the Earnings of Immigrants," Industrial and Labor Relations Review, 55(3), 473-492.

Fertig, M., and C. M. Schmidt (2001): "First- and Second-Generation Immigrants in Germany: What Do We Know and What Do People Think," Discussion Paper No. 286, IZA, Bonn.

Gang, I. N., And K. F. Zimmermann (2000): "Is Child like Parent? Educational Attainment and Ethnic Origin," Journal of Human Resources, 35(3), 550-569.

Haisken-DeNew, J., and J. Frick (2005): "Desktop Companion of the German SocioEconomic Panel," Discussion paper, DIW, Berlin.

Heckman, J., L. Lochner, And P. Todd (2005): "Earnings Functions, Rates of Return and Treatment Effects: The Mincer Equation and Beyond," Working Paper 11544, NBER.

Kirsten, C., and K. Granato (2007): "The Educational Attainment of the Second Generation in Germany: Social Origins and Ethnic Inequality," Discussion Paper No. 4, IAB, Nuremberg. 
Kreyenfeld, M., and D. Konietzka (2001): "The Transferability of Educational Credentials - The Case of Ethnic German Migrants in the German Labor Market," Working Paper 2001002, Max Planck Institute for Demographic Research, Rostock.

Licht, G., And V. Steiner (1994): “Assimilation, Labour Market Experience and Earnings Profiles of Temporary and Permanent Immigrant Workers in Germany," International Review of Applied Economics, 8(2), 130-156.

Mincer, J. (1974): Schooling, Experience and Earnings. National Bureau of Economic Research, New York.

OECD (2006): "Where Immigrant Students Succeed: A Comparative Review of Performance and Engagement in PISA," .

Riphahn, R. (2002): "Bruttoeinkommensverteilung in Deutschland 1984-1999 und Ungleichheit unter ausländischen Erwerbstätigen," Discussion Paper No. 272, DIW.

(2003): "Cohort Effects in the Educational Attainment of Second Generation Immigrants in Germany: An Analysis of Census Data," Journal of Population Economics, 16(4), $711-737$.

(2005): "Are there Diverging Time Trends in the Educational Attainment of Nationals and Second Generation Immigrants?," Jahrbücher für Nationalökonomie und Statistik, 225(3), $325-346$.

Schnepf, V. (2004): "How Different are Immigrants? A Cross-Country and Cross-Survey Analysis of Educational Attainment," Discussion Paper No. 1398, IZA, Bonn.

Statistisches Bundesamt (2006): Leben in Deutschland. Haushalte, Familien und Gesundheit Ergebnisse des Mikrozensus 2005. Statistisches Bundesamt, Wiesbaden. 
Tab. A.1: Estimation Results: Males

\begin{tabular}{|c|c|c|c|c|c|}
\hline & $\begin{array}{c}\text { Native } \\
\text { Germans }\end{array}$ & $\begin{array}{c}\text { People } \\
\text { with } \\
\text { migration } \\
\text { background }\end{array}$ & Foreigners & \begin{tabular}{|c|} 
thereof: \\
People with \\
migration \\
background \\
and German \\
citizenship
\end{tabular} & $\begin{array}{l}\text { German } \\
\text { resettler } \\
\text { (ethnic } \\
\text { Germans) }\end{array}$ \\
\hline Age & $0.1651^{* * *}$ & $0.1340^{* * *}$ & $0.1634^{* * *}$ & $0.1148^{* * *}$ & $0.1839^{* * *}$ \\
\hline Age (squared) & $-0.0017^{* * *}$ & $-0.0015^{* * *}$ & $-0.0019^{* * *}$ & $-0.0013^{* * *}$ & $-0.0021^{* * *}$ \\
\hline \multicolumn{6}{|l|}{ Education } \\
\hline Medium-skilled $^{\mathrm{a}}$ & $2.2140^{* * *}$ & $1.7753^{* * *}$ & $1.9488^{* * *}$ & $1.5970^{* * *}$ & $2.7939^{* * *}$ \\
\hline High-skilled ${ }^{\mathrm{b}}$ & $1.3125^{* * *}$ & $1.4305^{* * *}$ & 0.6880 & $1.1091^{* * *}$ & $3.5535^{* * *}$ \\
\hline \multicolumn{6}{|l|}{ Interaction with age } \\
\hline Medium-skilled $\times$ Age & $-0.1003^{* * *}$ & $-0.0774^{* * *}$ & $-0.0889^{* * *}$ & $-0.0688^{* * *}$ & $-0.1290^{* * *}$ \\
\hline High-skilled $\times$ Age & $-0.0542^{* * *}$ & $-0.0614^{* * *}$ & -0.0312 & $-0.0430^{* * *}$ & $-0.1682^{* * *}$ \\
\hline \multicolumn{6}{|c|}{ Interaction with age (squared) } \\
\hline Medium-skilled×Age(squared) & $0.0011^{* * *}$ & $0.0008^{* * *}$ & $0.0010^{* * *}$ & $0.0007^{* * *}$ & $0.0015^{* * *}$ \\
\hline High-skilled ×Age(squared) & $0.0007^{* * *}$ & $0.0007^{* * *}$ & 0.0004 & $0.0005^{* *}$ & $0.0020^{* * *}$ \\
\hline \multicolumn{6}{|l|}{ Economic Sectors } \\
\hline Industry & $0.1257^{* * *}$ & -0.0207 & -0.0964 & -0.0039 & 0.0465 \\
\hline Transportation & $0.0796^{* * *}$ & -0.0602 & -0.1534 & -0.0274 & -0.0467 \\
\hline Construction & $0.0725^{* * *}$ & $-0.0825^{*}$ & -0.1255 & $-0.0859^{*}$ & 0.0239 \\
\hline Trading services & $0.0792^{* * *}$ & $-0.0974^{* *}$ & -0.1022 & $-0.1031^{*}$ & -0.0507 \\
\hline Social services and health & $0.0608^{* * *}$ & $-0.1385^{* * *}$ & $-0.2489^{*}$ & $-0.0963^{*}$ & -0.0892 \\
\hline Self-employment & $-0.0537^{* * *}$ & $0.0860^{* * *}$ & 0.0674 & $0.1022^{* * *}$ & $0.1724^{*}$ \\
\hline Part time work & $0.0456^{* * *}$ & $0.0475^{*}$ & 0.0834 & -0.0049 & $0.2210^{* * *}$ \\
\hline Time of residence in Germany & & $0.0051^{* * *}$ & 0.0043 & $0.0057^{* *}$ & $0.0187^{*}$ \\
\hline $\begin{array}{l}\text { Time of residence in Germany } \\
\text { (squared) }\end{array}$ & & 0.0000 & 0.0001 & 0.0000 & -0.0002 \\
\hline \multicolumn{6}{|l|}{ Region $^{\mathrm{c}}$} \\
\hline North & $-0.0700^{* * *}$ & $-0.0664^{* *}$ & -0.0031 & $-0.0809^{* *}$ & -0.0591 \\
\hline Center & $-0.0206^{*}$ & $-0.0559^{* * *}$ & $-0.0917^{* *}$ & -0.0343 & -0.0564 \\
\hline \multicolumn{6}{|l|}{ Dummy for years } \\
\hline Year 2 & $0.0224^{* *}$ & $0.0257^{*}$ & -0.0033 & 0.0239 & $0.0679^{* *}$ \\
\hline Year 3 & -0.0112 & 0.0067 & -0.0195 & 0.0137 & 0.0083 \\
\hline Year 4 & $-0.0265^{* * *}$ & -0.0040 & -0.0316 & 0.0030 & -0.0013 \\
\hline Year 5 & -0.0071 & -0.0068 & -0.0155 & 0.0002 & -0.0167 \\
\hline Year 6 & 0.0002 & -0.0216 & -0.0202 & -0.0156 & -0.0367 \\
\hline Year 7 & -0.0022 & -0.0191 & -0.0071 & -0.0115 & -0.0486 \\
\hline Year 8 & $0.0145^{*}$ & 0.0086 & -0.0139 & 0.0232 & -0.0073 \\
\hline Year 9 & $0.0315^{* * *}$ & $0.0459^{* * *}$ & 0.0530 & $0.0605^{* * *}$ & -0.0080 \\
\hline Year 10 & $0.0155^{*}$ & 0.0150 & 0.0119 & $0.0358^{*}$ & -0.0533 \\
\hline Year 11 & 0.0044 & -0.0111 & -0.0242 & 0.0095 & -0.0660 \\
\hline Constant & $-1.2059^{* * *}$ & $-0.5076^{* * *}$ & $-0.9639^{* * *}$ & -0.1408 & $-1.5987^{* * *}$ \\
\hline$\sigma_{u}$ & 0.310 & 0.286 & 0.303 & 0.274 & 0.261 \\
\hline$\rho$ & .702 & .620 & .613 & .612 & .625 \\
\hline No. of persons & 6587 & 1976 & 532 & 1265 & 339 \\
\hline No. of obs. & 29379 & 9069 & 1940 & 5594 & 1535 \\
\hline
\end{tabular}


Tab. A.2: Estimation Results: Females

\begin{tabular}{|c|c|c|c|c|c|}
\hline & $\begin{array}{c}\text { Native } \\
\text { Germans }\end{array}$ & $\begin{array}{c}\text { People } \\
\text { with } \\
\text { migration } \\
\text { background }\end{array}$ & Foreigners & \begin{tabular}{|c|} 
thereof: \\
People with \\
migration \\
background \\
and German \\
citizenship
\end{tabular} & $\begin{array}{l}\text { German } \\
\text { resettler } \\
\text { (ethnic } \\
\text { Germans) }\end{array}$ \\
\hline Age & $0.1375^{* * *}$ & $0.1001^{* * *}$ & $0.1343^{* * *}$ & $0.0901^{* * *}$ & $0.1029^{* * *}$ \\
\hline Age (squared) & $-0.0015^{* * *}$ & $-0.0011^{* * *}$ & $-0.0015^{* * *}$ & $-0.0010^{* * *}$ & $-0.0011^{* * *}$ \\
\hline \multicolumn{6}{|l|}{ Education } \\
\hline Medium-skilled $^{\mathrm{a}}$ & $2.1254^{* * *}$ & $1.5228^{* * *}$ & $1.9661^{* * *}$ & $1.4413^{* * *}$ & $1.6138^{* * *}$ \\
\hline High-skilled $^{\mathrm{b}}$ & $1.1141^{* * *}$ & $1.0879^{* * *}$ & $2.0245^{* * *}$ & 0.7360 & 0.6693 \\
\hline \multicolumn{6}{|l|}{ Interaction with age } \\
\hline Medium-skilled $\times$ Age & $-0.0957^{* * *}$ & $-0.0610^{* * *}$ & $-0.0847^{* * *}$ & $-0.0584^{* * *}$ & $-0.0700^{* * *}$ \\
\hline High-skilled × Age & $-0.0412^{* * *}$ & $-0.0409^{* *}$ & $-0.0865^{* * *}$ & -0.0211 & -0.0277 \\
\hline \multicolumn{6}{|l|}{ Interaction with age (squared) } \\
\hline Medium-skilled×Age(squared) & $0.0011^{* * *}$ & $0.0006^{* * *}$ & $0.0009^{* * *}$ & $0.0006^{* * *}$ & $0.0008^{* * *}$ \\
\hline High-skilled $\times$ Age $($ squared $)$ & $0.0005^{* * *}$ & $0.0005^{* *}$ & $0.0010^{* *}$ & 0.0002 & 0.0004 \\
\hline \multicolumn{6}{|l|}{ Economic Sectors } \\
\hline Industry & $0.1266^{* * *}$ & -0.0517 & 0.2662 & 0.0020 & $-0.2785^{*}$ \\
\hline Transportation & $0.0972^{* *}$ & -0.0577 & 0.2606 & -0.0088 & $-0.2931^{*}$ \\
\hline Construction & $0.1297^{* * *}$ & -0.0338 & 0.2500 & 0.0149 & -0.2685 \\
\hline Trading services & $0.0674^{*}$ & -0.1067 & 0.1749 & -0.0523 & $-0.3296^{*}$ \\
\hline Social services and health & $0.1551^{* * *}$ & -0.0380 & 0.3098 & -0.0288 & -0.2190 \\
\hline Self-employment & $-0.0277^{*}$ & 0.0317 & 0.0636 & $0.0870^{*}$ & $-0.3940^{* * *}$ \\
\hline Part time work & -0.0002 & 0.0134 & 0.0241 & 0.0100 & 0.0204 \\
\hline Time of residence in Germany & & $0.0141^{* * *}$ & $0.0156^{* * *}$ & $0.0111^{* * *}$ & $0.0464^{* * *}$ \\
\hline $\begin{array}{l}\text { Time of residence in Germany } \\
\text { (squared) }\end{array}$ & & $-0.0001^{* * *}$ & -0.0001 & -0.0001 & $-0.0007^{* * *}$ \\
\hline \multicolumn{6}{|l|}{ Region $^{\mathrm{c}}$} \\
\hline North & $-0.0286^{*}$ & $-0.0797^{* *}$ & -0.0756 & $-0.0792^{*}$ & -0.0894 \\
\hline Center & $-0.0242^{*}$ & $-0.0737^{* * *}$ & $-0.1042^{* *}$ & $-0.0558^{*}$ & -0.0472 \\
\hline \multicolumn{6}{|l|}{ Dummy for years } \\
\hline Year 2 & $0.0200^{*}$ & 0.0201 & 0.0210 & $0.0516^{* *}$ & $-0.0962^{*}$ \\
\hline Year 3 & 0.0080 & 0.0042 & 0.0344 & 0.0030 & -0.0583 \\
\hline Year 4 & $0.0219^{*}$ & 0.0052 & -0.0271 & 0.0261 & $-0.0956^{*}$ \\
\hline Year 5 & $0.0304^{* *}$ & 0.0191 & 0.0119 & $0.0453^{*}$ & $-0.1350^{* *}$ \\
\hline Year 6 & $0.0279^{* *}$ & 0.0204 & 0.0513 & 0.0293 & $-0.1268^{* *}$ \\
\hline Year 7 & $0.0196^{*}$ & 0.0210 & 0.0454 & 0.0399 & $-0.1525^{* *}$ \\
\hline Year 8 & $0.0604^{* * *}$ & $0.0569^{* * *}$ & 0.0827 & $0.0757^{* * *}$ & $-0.1397^{* *}$ \\
\hline Year 9 & $0.0733^{* * *}$ & $0.0573^{* *}$ & $0.1038^{*}$ & $0.0661^{* *}$ & $-0.1653^{* *}$ \\
\hline Year 10 & $0.0781^{* * *}$ & $0.0570^{* *}$ & 0.0710 & $0.0672^{* *}$ & $-0.1452^{*}$ \\
\hline Year 11 & $0.0739^{* * *}$ & 0.0288 & 0.0623 & 0.0174 & $-0.1608^{* *}$ \\
\hline Constant & $-0.8491^{* * *}$ & -0.2260 & $-1.1904^{* * *}$ & -0.0528 & -0.1422 \\
\hline$\sigma_{u}$ & 0.339 & 0.298 & 0.280 & 0.311 & 0.277 \\
\hline$\rho$ & .664 & .607 & .552 & .648 & .575 \\
\hline No. of persons & 5937 & 1504 & 442 & 889 & 298 \\
\hline No. of obs. & 24324 & 6183 & 1510 & 3452 & 1221 \\
\hline
\end{tabular}

${ }^{a}$ Medium-skilled are people with completed professional training.

b High-skilled are people with advanced technical college or university degree.

c North contains the Federal Laender of Schleswig-Holstein, Hamburg, Lower-Saxony, Bremen, and Berlin. Center are the Federal Laender North Rhine-Westphalia, Rhineland-Palatinate, and Saarland. South comprises Hesse, Bavaria, and Baden-Wuerttemberg. 
Fig. A.1: Wage Profiles: Native Germans vs. Foreigners

Low-skilled

Males

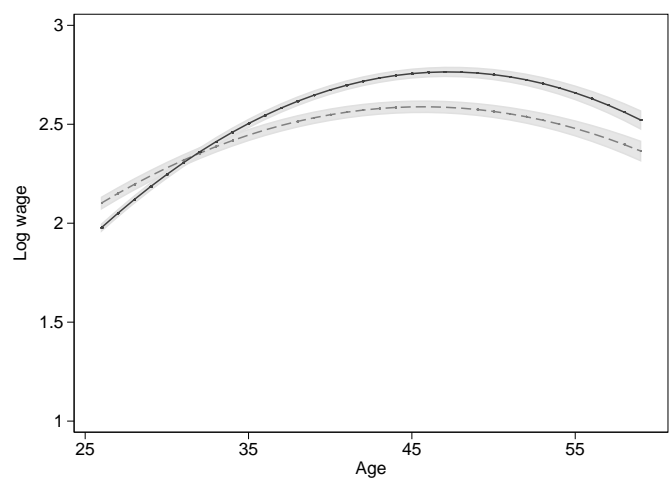

Females

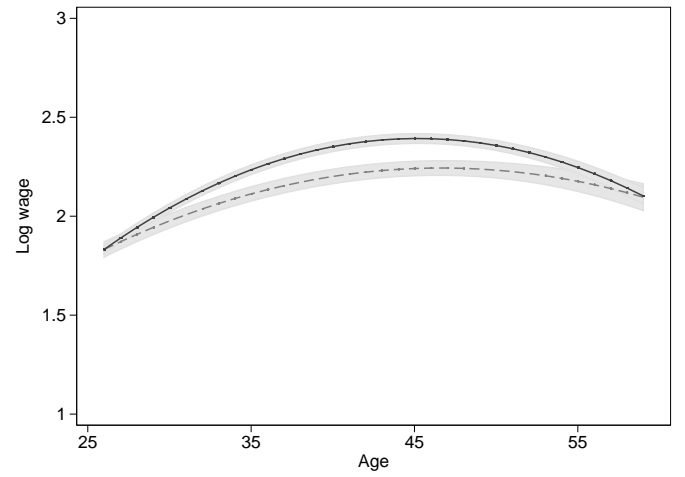

Medium-skilled

Males

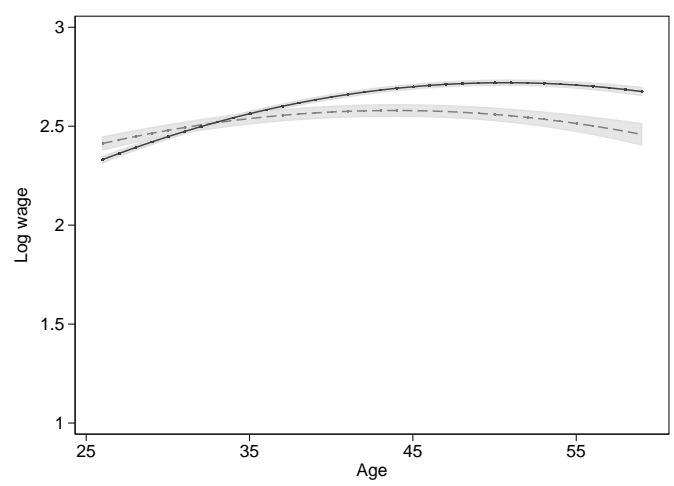

Females

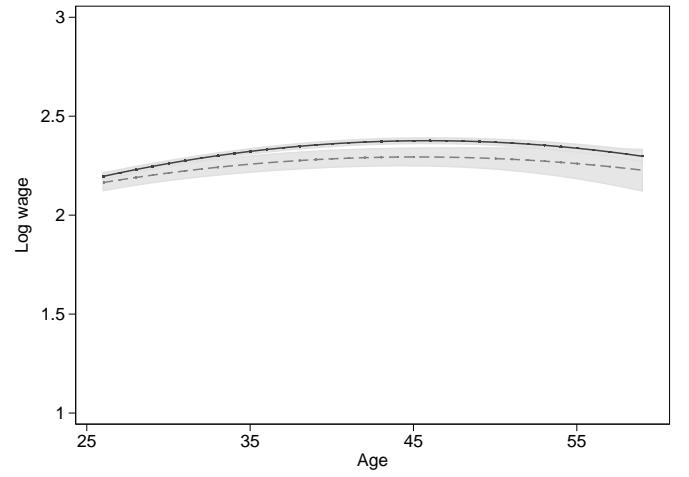

High-skilled

Males

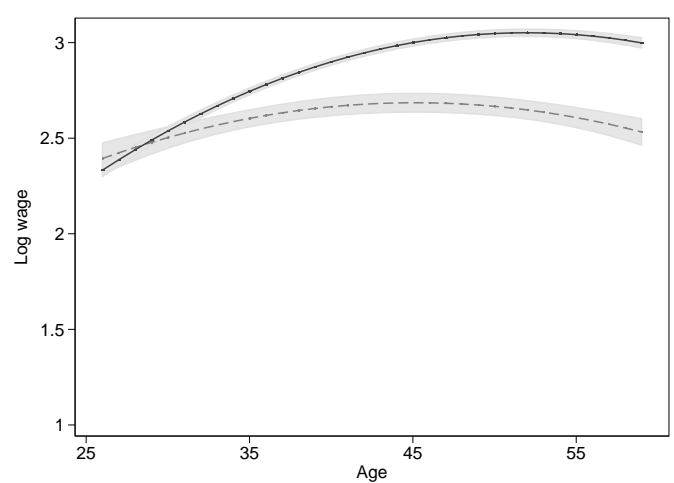

Females

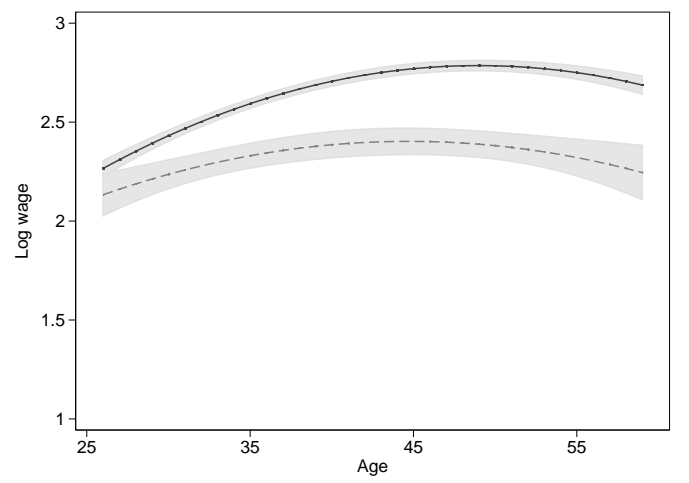

Solid line $(-)$ refers to native Germans, dashed line $(--)$ refers to foreigners. $95 \%$ confidence limits are shaded grey. 
Fig. A.2: Wage Profiles: Native Germans vs. German Citizens (2000-2005 panel) Low-skilled

Males

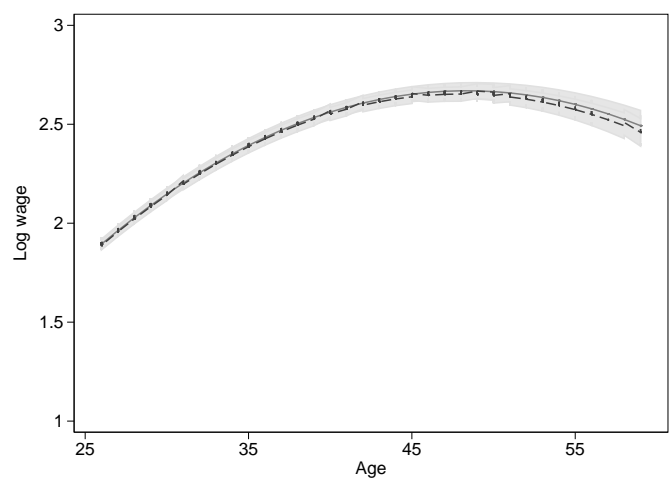

Females

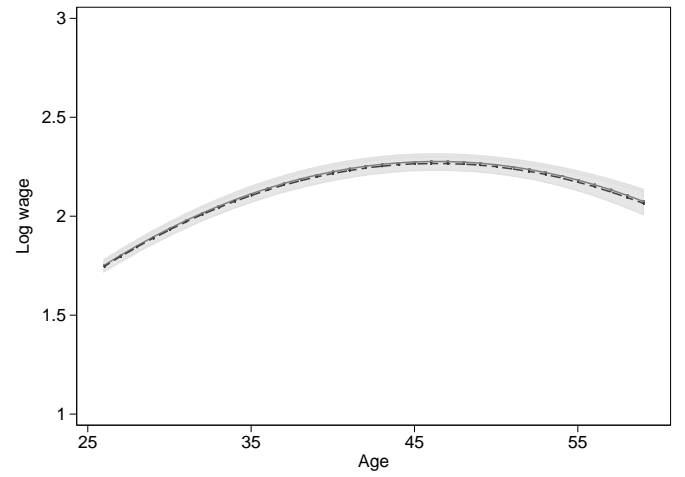

Medium-skilled

Males

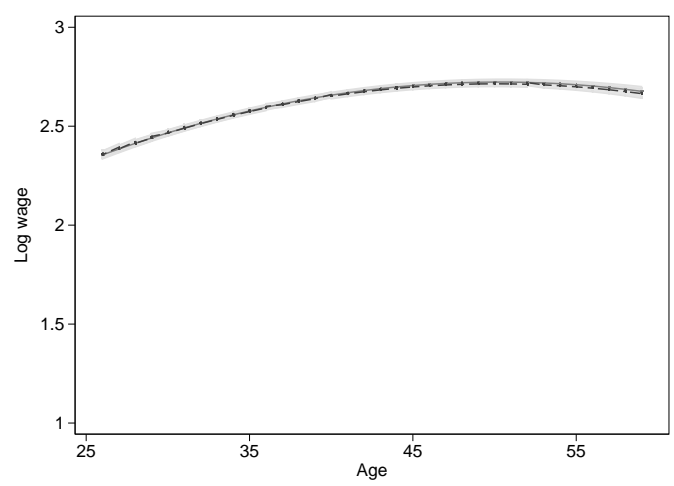

Females

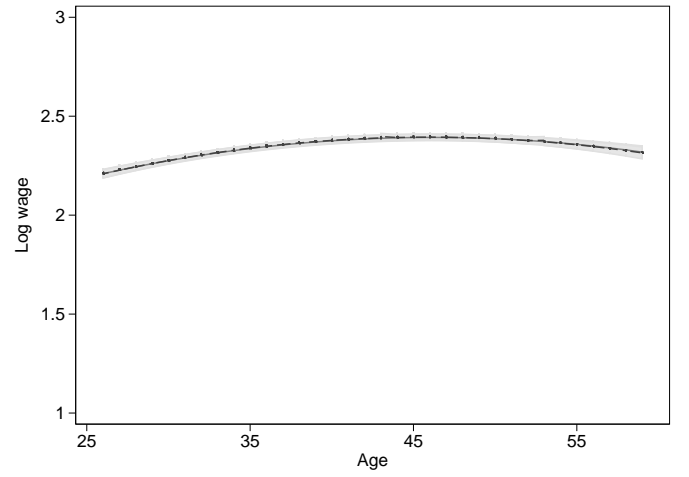

High-skilled

Males

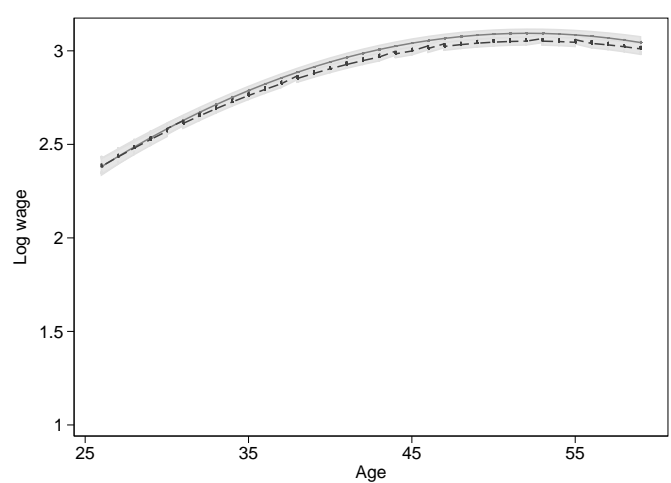

Females

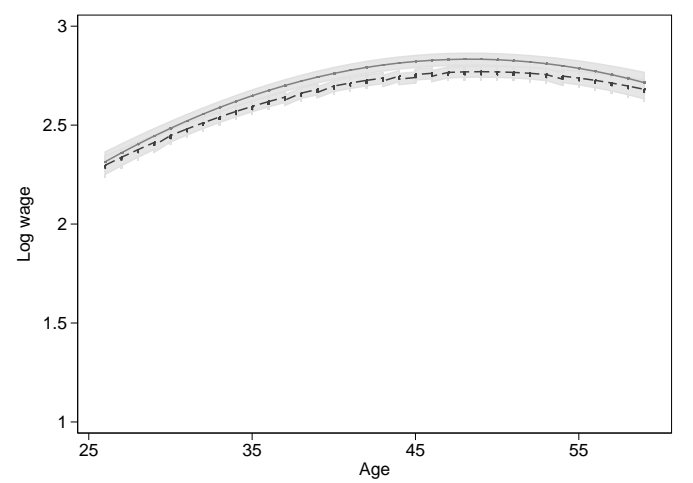

Solid line (-) refers to native Germans, dashed line (- - ) refers to German citizens. $95 \%$ confidence limits are shaded grey. 
Fig. A.3: Wage Profiles: Foreigners vs. German Citizens with Migration Background (2000-2005 panel)

Low-skilled

Males

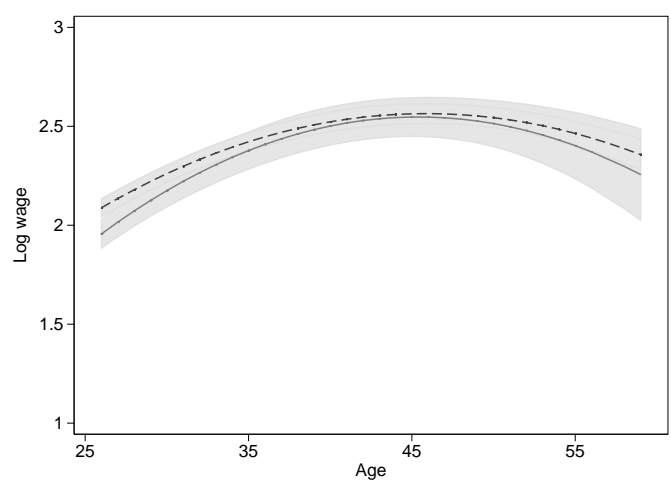

Females

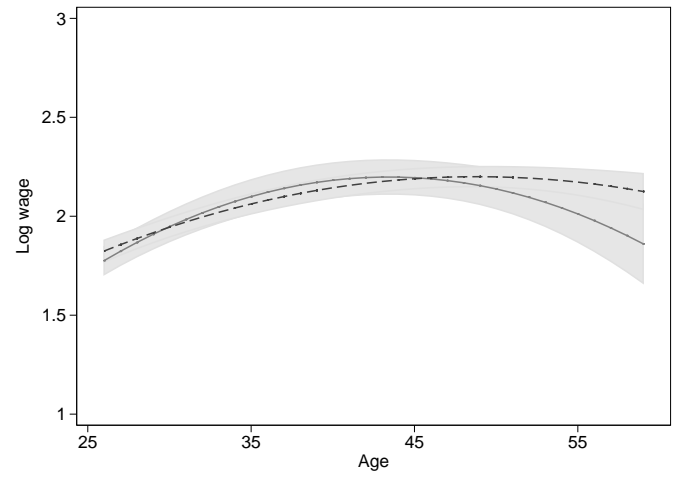

Medium-skilled

Females
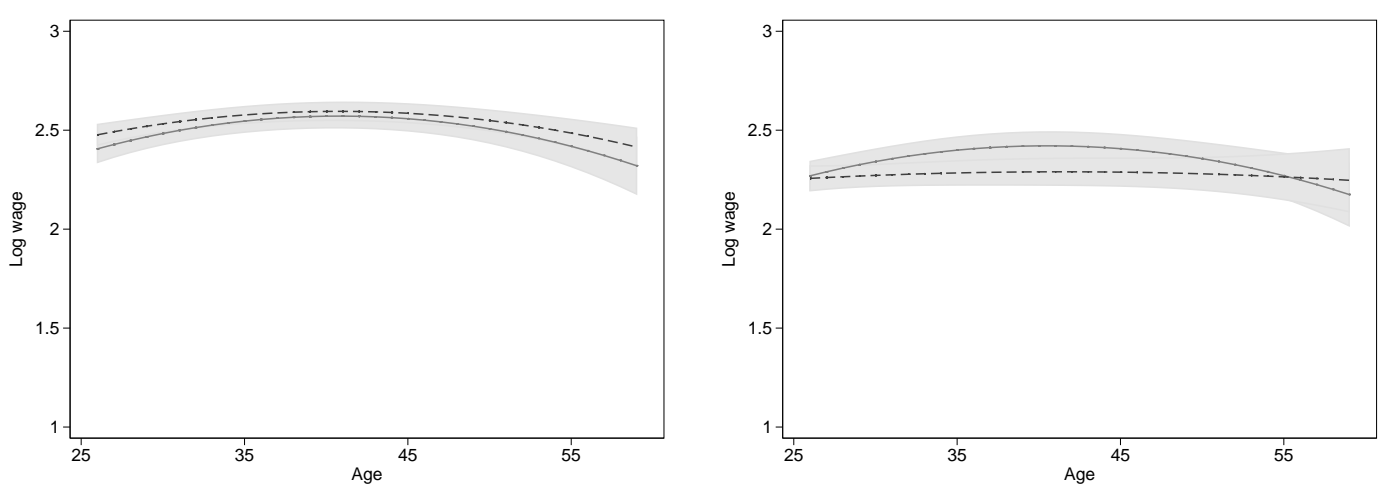

High-skilled

Males

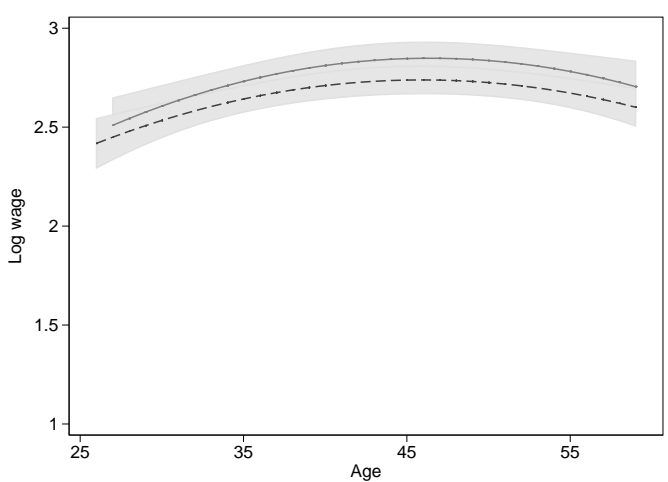

Females

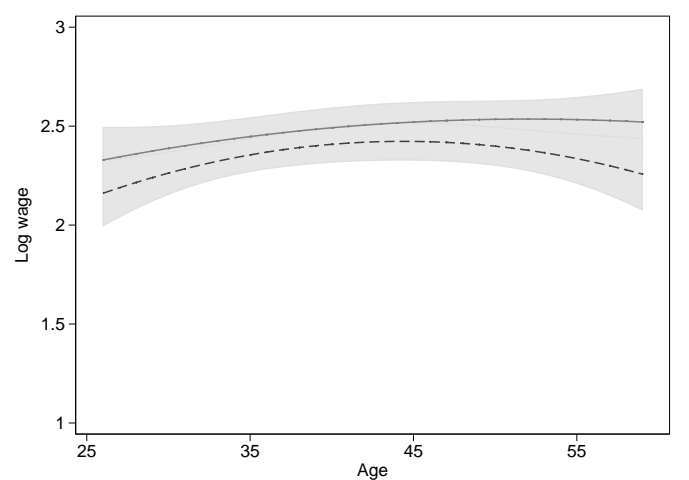

Solid line (-) refers to German citizens with migration background, dashed line $(--)$ refers to foreigners. $95 \%$ confidence limits are shaded grey. 